\title{
POLY(TRIMETHYLENE CARBONATE) AND BIPHASIC CALCIUM PHOSPHATE COMPOSITES FOR ORBITAL FLOOR RECONSTRUCTION: A FEASIBILITY STUDY IN SHEEP
}

\author{
A.C. van Leeuwen ${ }^{1, *}$, H. Yuan²,3, G. Passanisi², J.W. van der Meer ${ }^{4}$, J.D. de Bruijn ${ }^{2,5,6}$, T.G. van Kooten ${ }^{7}$, \\ D.W. Grijpma ${ }^{6,7}$ and R.R.M. Bos ${ }^{1}$
}

\begin{abstract}
${ }^{1}$ Department of Oral and Maxillofacial Surgery, University Medical Centre Groningen, Groningen, The Netherlands ${ }^{2}$ Xpand Biotechnology, Bilthoven, The Netherlands

${ }^{3}$ MIRA Institute for Biomedical Engineering and Technical Medicine, Department of Tissue Regeneration, University of Twente, Enschede, The Netherlands

${ }^{4}$ Department of Orthodontics, University Medical Centre Groningen, Groningen, The Netherlands ${ }^{5}$ School of Engineering and Materials Science, Queen Mary University of London, London, United Kingdom ${ }^{6}$ MIRA Institute for Biomedical Engineering and Technical Medicine,

Department of Biomaterials Science and Technology, University of Twente, Enschede, The Netherlands ${ }^{7}$ W.J. Kolff Institute, Department of Biomedical Engineering, University Medical Centre Groningen and University of Groningen, Groningen, The Netherlands
\end{abstract}

\begin{abstract}
In the treatment of orbital floor fractures, bone is ideally regenerated. The materials currently used for orbital floor reconstruction do not lead to the regeneration of bone. Our objective was to render polymeric materials based on poly(trimethylene carbonate) (PTMC) osteoinductive, and to evaluate their suitability for use in orbital floor reconstruction. For this purpose, osteoinductive biphasic calcium phosphate $(\mathrm{BCP})$ particles were introduced into a polymeric PTMC matrix. Composite sheets containing $50 \mathrm{wt} \%$ BCP particles were prepared. Also laminates with poly(D,L-lactide) (PDLLA) were prepared by compression moulding PDLLA films onto the composite sheets. After sterilisation by gamma irradiation, the sheets were used to reconstruct surgically-created orbital floor defects in sheep. The bone inducing potential of the different implants was assessed upon intramuscular implantation.

The performance of the implants in orbital floor reconstruction was assessed by cone beam computed tomography (CBCT). Histological evaluation revealed that in the orbital and intramuscular implantations of BCP containing specimens, bone formation could be seen after 3 and 9 months. Analysis of the CBCT scans showed that the composite PTMC sheets and the laminated composite sheets performed well in orbital floor reconstruction. It is concluded that PTMC/BCP composites and PTMC/BCP composites laminated with PDLLA have osteoinductive properties and seem suitable for use in orbital floor reconstruction.
\end{abstract}

Keywords: Synthetic composite materials; osteoconductive; osteoinductive; orbital floor fracture; bone formation.

*Address for correspondence:

A.C. van Leeuwen

Department Oral and Maxillofacial Surgery

University Medical Center Groningen

PO Box 30.001, 9700 RB Groningen, The Netherlands

E-mail: a.van.leeuwen01@umcg.nl

\section{Introduction}

Orbital floor fractures are a common result of injury to the orbit. Herniation of orbital fat and/or entrapment of ocular muscle can be avoided by reconstructing the bony orbital floor. The use of autologous bone grafts is considered to be the 'gold standard' for repair and reconstruction of bony defects in orbital floor fractures. However, the method has several disadvantages among which are: the extra operation time, the accompanying donor-site morbidity and the poor predictability of the resorption rate of autologous bone (Giannoudis et al., 2005). To avoid these drawbacks, implants prepared from (non-resorbable) materials like titanium, polytetrafluoroethylene, polyethylene and silicone rubbers have been applied in the treatment of orbital floor fractures (Ellis and Messo, 2004; Prowse et al., 2010). Being able to use biodegradable and resorbable implant materials would be of great interest, as the use of permanent implants is associated with the life-long risk of infections. However, after degradation of biodegradable materials, the formed fibrous capsule that remains might not be sufficiently rigid to prevent late enophthalmos. This is especially relevant when reconstructing large orbital floor defects (Kontio et al., 2004; Jaquiery et al., 2007; Kontio and Lindqvist, 2009). New bone formation during healing of the fractured orbit would therefore be highly desirable. Poly(lactide)s and poly(glycolide)s are biodegradable polymers that have most often been investigated (Eppley and Prevel, 1997; Potter and Ellis, 2004). Upon degradation of these polymers, however, acidic compounds are formed. These compounds can have a detrimental effect on surrounding (bone) tissues, and hinder the formation of new bone (Taylor et al., 1994; Wu and Ding, 2004).

As a result of its osteogenic and osteoinductive properties, bone formation in orbital floor reconstruction currently only occurs when autologous bone is used. To obtain a synthetic implant material that leads to formation of bone in bony defects, osteoinductive or osteoconductive properties are required. It has been shown in several animal studies, that calcium phosphate ceramics with specific surface microstructures have osteoinductive properties (Malard et al., 1999; Ripamonti, 1996; Le Nihouannen 
et al., 2005; Habibovic et al., 2006; Fellah et al., 2008; Fellah et al., 2010; Yuan et al., 2010). Unfortunately, these (sintered) ceramic materials are brittle and difficult to obtain in a specific shape. To overcome these drawbacks, composite materials have been prepared by introducing the calcium phosphates into polymeric matrices (Greish and Brown, 2001; Ignatius et al., 2001; Kikuchi et al., 2002; Guan and Davies, 2004; Dorozhkin, 2009). This was shown to improve both mechanical and handling properties. Hence, composite materials based on bone-inducing microstructured biphasic calcium phosphate $(\mathrm{BCP})$ and a polymeric matrix of poly(trimethylene carbonate) (PTMC) seem interesting.

PTMC is an amorphous polymer with a relatively low elastic modulus of 5 to $7 \mathrm{MPa}$ at room temperature. PTMC degrades enzymatically in vivo by a surface erosion process without the formation of acidic degradation products (Pego et al., 2003b; Zhang et al., 2006). The polymer has not been shown to calcify or lead to the formation of new bone upon implantation. Furthermore, it has been shown that PTMC does not exert negative effects on bone (such as osteolysis) and ocular tissue (Habraken et al., 2008; Jansen et al., 2011; Liao et al., 2011).

We recently prepared composite materials consisting of PTMC and calcium phosphate ceramics (Van Leeuwen et al., 2012b) and described their mechanical properties. It was shown that incorporation of calcium phosphate particles increased the flexural modulus of the composite.

It is hypothesised that the composite materials will have osteoinductive properties as the BCP will become exposed during degradation of the PTMC matrix.

This paper describes the preparation and in vivo evaluation of composite materials based on microstructured BCP and PTMC. Although implant materials with (relatively) low elasticity modulus values such as silicone have been quite effective in reconstructing (small) orbital floor defects (Prowse et al., 2010), the reconstruction of large defects might necessitate the use of more rigid materials. To allow the reconstruction of large orbital floor defects, we also prepared laminates of the composite materials with a single thin layer of poly(D,L-lactide) (PDLLA). In preparing these structures, however, we ensured that the PDLLA component was in minimal contact with the calcium phosphate particles, and that only small amounts of PDLLA are used. This has been described in more detail in previous work (Van Leeuwen et al., 2012b).

\section{Materials and Methods}

\section{Materials}

Polymerisation grade 1,3-trimethylene carbonate (TMC) was obtained from Boehringer Ingelheim, Germany. Stannous octoate ( $\mathrm{SnOct}_{2}$ from Sigma-Aldrich, St. Louis, MO, USA) was used as received. High molecular weight poly(D,L-lactide) (PDLLA, with a 50/50 molar ratio of L- to D-lactide) was obtained from Purac Biochem, (Gorinchem, The Netherlands), and used as received.

Biphasic calcium phosphate ceramic, $(20 \pm 3 \mathrm{wt} \%$ beta-tricalcium phosphate $(\beta$-TCP) and $80 \pm 3 \mathrm{wt} \%$ hydroxyapatite (HA)), which was sintered at $1150{ }^{\circ} \mathrm{C}$ for $8 \mathrm{~h}$ and sieved to particle sizes $45-150 \mu \mathrm{m}$ according to Habibovic et al. (Habibovic et al., 2006), was obtained from Xpand Biotechnology (Bilthoven, The Netherlands).

The BCP particles exhibited a surface microstructure that results from the surface microporosity and the small grain size of the particles (Yuan et al., 1999). The particles had a microporosity of $17 \%$ and a specific surface of $1.0 \mathrm{~m}^{2} / \mathrm{g}$. The used solvents were of technical grade and purchased from Biosolve (Valkenswaard, The Netherlands).

\section{Preparation of composites and laminates}

Poly(trimethylene carbonate) (PTMC) was prepared by ring opening polymerisation of trimethylene carbonate at $130{ }^{\circ} \mathrm{C}$ for a period of 3 days. Stannous octoate was used as a catalyst at a concentration of $2 \times 10^{-4} \mathrm{~mol}$ per mol of monomer. Analysis of the synthesised polymer by proton nuclear magnetic resonance ( $\left.{ }^{1} \mathrm{H}-\mathrm{NMR}\right)$, gel permeation chromatography (GPC) and differential scanning calorimetry (DSC) according to procedures described earlier (Pego et al., 2003a) indicated that high molecular weight polymer had been synthesised. GPC measurements showed that $\mathrm{Mw}=414,000 \mathrm{~g} / \mathrm{mol}$ and $\mathrm{Mn}=316,000 \mathrm{~g} /$ mol, while nuclear magnetic resonance (NMR) indicated that monomer conversion was more than $98 \%$.

The glass transition temperature of this amorphous polymer was approximately $-17^{\circ} \mathrm{C}$, as thermal analysis showed (Pego et al., 2003a).

The PTMC polymer was purified by dissolving in chloroform and precipitation into an excess of ethanol. Similarly, composites of PTMC with BCP particles were prepared by dissolving PTMC in chloroform at a concentration of $5 \mathrm{~g} / 100 \mathrm{~mL}$, after which the BCP was added and dispersed in the solution by magnetic stirring. The uniform dispersion was then precipitated into a fivefold excess of ethanol $100 \%$. The composite precipitate was collected and dried under vacuum at room temperature until constant weight was reached. PTMC/BCP composites containing $50 \mathrm{wt} \%$ (corresponding to $30 \mathrm{vol} \%$ ) of $\beta$ TCP were prepared.

After drying, the purified PTMC and the composite precipitate were compression moulded into $1.5 \mathrm{~mm}$ thick sheets at $140{ }^{\circ} \mathrm{C}$ and a pressure of $3.0 \mathrm{MPa}$ using a Carver model 3851-0 laboratory press (Carver, Wabash, IN, USA). The poly(D,L-lactide) was also of high molecular weight, and had an $\mathrm{Mw}=234,000 \mathrm{~g} / \mathrm{mol}$ and an $\mathrm{Mn}=178,000 \mathrm{~g} /$ mol. NMR indicated that the residual monomer content was less than $1 \%$. The glassy polymer was also amorphous, and had a glass transition temperature of approximately $52^{\circ} \mathrm{C}$. This polymer was compression moulded into $0.3 \mathrm{~mm}$ thick sheets at $140{ }^{\circ} \mathrm{C}$.

Laminates of the PTMC/BCP composites and PDLLA were prepared by compression moulding PDLLA sheets onto sheets of the composite material at $140{ }^{\circ} \mathrm{C}$. The PTMC/BCP composite layer was $1.2 \mathrm{~mm}$ thick, while the PDLLA layer was $0.3 \mathrm{~mm}$ thick.

The prepared sheets were then sealed under vacuum and exposed to $25 \mathrm{kGy}$ gamma irradiation from a ${ }^{60} \mathrm{Co}$ source (Isotron, Ede, The Netherlands) for sterilisation. 


\section{Experimental design of the animal study}

All procedures performed on the animals were done according to international standards on animal welfare as well as being compliant with the Animal Research Committee of the University Medical Centre Groningen.

Ten full-grown female Dutch Texel sheep were operated on and (evenly) divided into two groups. The first group had a follow-up of 3 months, the second a follow-up of 9 months. Critical size defects measuring 2.5-3.0 $\mathrm{cm}^{2}$ (Kontio et al., 2004) were created in both orbital floors and reconstructed with: (1) a PTMC sheet, (2) a composite (PTMC/BCP) sheet or (3) a laminated composite (PTMC/ BCP-PDLLA) sheet. Regarding the laminated composite, the PDLLA layer faced the maxillary sinus.

To be able to distinguish between osteoinductivity and osteoconductivity, bone formation is generally evaluated in a non-bony environment (Urist, 1965; Urist et al., 1967; Habibovic et al., 2006; Barradas et al., 2011). To assess osteoinductive properties of our materials, samples $(1.5 \mathrm{~mm} \times 10 \mathrm{~mm}$ diameter $)$ of the prepared sheets, as well as $1 \mathrm{~mL}$ of the used BCP particles, were implanted intramuscularly in the back of the sheep.

For the orbital floor implantations, multiple different materials were implanted in individual animals in a randomised manner. The same materials were also implanted intramuscularly. Furthermore, BCP was implanted intramuscularly in each animal as well. An overview of the performed implantations is provided in Table 1.

To determine the position of the reconstructed orbital floor, all sheep were evaluated by cone-beam computed tomography (CBCT) 1 week before and 1 week after surgery, and at the time of termination. To monitor bone formation over time, fluorochrome markers were administered at 3, 6 and 9 weeks after surgery and at 30, 33 and 36 weeks for respectively the 3 and the 9 month group. Bone formation was evaluated by histology and histomorphometry of non-decalcified sections using epifluorescent confocal and conventional light microscopy.

\section{Surgical procedure and fluorochrome labelling}

Ten adult full-grown female Dutch Texel sheep, aged 2436 months, were acquired and allowed to acclimatise for two weeks. The surgical procedures were performed under general anaesthesia. After the subciliar area was shaved and disinfected, both orbital floors were exposed using an infraorbital approach. The periosteum was elevated and the floor was fractured using a burr and/or a chisel. Bone fragments were removed from the defect site. The bony defects created were approximately circular measured 2.5$3.0 \mathrm{~cm}^{2}$ in size. Then the orbital floor was reconstructed using one of the implant materials (PTMC, PTMC/BCP composite or laminated PTMC/BCP-PDLLA composite sheet). The size of the implant was cut with a pair of scissors to fit the orbit, while care was taken to ensure that the defect was completely covered. In this first study, implants were fixed with one titanium screw $(1.5 \times 3.5 \mathrm{~mm}$, KLS-Martin, Tuttlingen, Germany) to prevent dislocation. After reconstruction, the orbital periosteum was incised to mimic a traumatic situation (the incision allowed the orbital fat and musculature to prolapse into the orbit). The wound
Table 1: Overview of implantations and implantation sites for the experimental 3 and 9 month implantation groups.

\begin{tabular}{|l|l|l|}
\hline Implantation material & 3 months & 9 months \\
\hline BCP particles & IM: $n=5$ & IM: $n=5$ \\
\hline \multirow{2}{*}{ PTMC } & OF: $n=3$ & OF: $n=3$ \\
& IM: $n=3$ & IM: $n=3$ \\
\hline \multirow{2}{*}{ PTMC/BCP composite } & OF: $n=4$ & OF: $n=4$ \\
& IM: $n=4$ & IM: $n=4$ \\
\hline PTMC/BCP-PDLLA & OF: $n=3$ & OF: $n=3$ \\
laminated composite & IM: $n=3$ & IM: $n=3$ \\
\hline
\end{tabular}

OF: orbital floor

IM: intramuscular

was closed in layers with resorbable sutures (Polyglactin 910, Ethicon, Johnson \& Johnson, New Brunswick, NJ, USA). At the same time, samples were implanted intramuscularly in the paraspinal muscles. The muscle fascia was closed with non-resorbable sutures to mark the different implantation sites in the back (Polypropylene, Ethicon). The other layers were closed with resorbable sutures. Prior to surgery amoxicillin $(15 \mathrm{mg} / \mathrm{kg})$ was administered and continued for 6 days postoperative. Buprenorphin was administered for peri- and postoperative pain relief.

Fluorochrome markers were administered at the previously mentioned time points prior to termination. Calcein Green (10 mg/kg intravenously, Sigma-Aldrich) was administered at 3 weeks and at 30 weeks, Xylenol Orange $(100 \mathrm{mg} / \mathrm{kg}$ intravenously, Sigma-Aldrich) at 6 weeks and at 33 weeks and Oxytetracyclin (Engemycine $32 \mathrm{mg} / \mathrm{kg}$ intramuscularly, Mycofarm, Braintree, UK) at 9 weeks and at 36 weeks after surgery. $\mathrm{NaHCO}_{3}$ and saline solutions were used as solvents. After 3 and 9 months follow-up, the animals were sacrificed by injecting an overdose of pentobarbital (Organon, Oss, The Netherlands), and the implantation areas were retrieved and fixed in a $4 \%$ phosphate-buffered formalin solution.

\section{Histological preparation}

The fixed samples were rinsed with phosphate buffered saline (PBS), dehydrated in a series of ethanol solutions $(70 \%, 80 \%, 90 \%, 96 \%, 100 \% \times 2)$ and embedded in methyl methacrylate (LTI, Bilthoven, The Netherlands). Using a modified diamond saw (Klein et al., 1994) (Leica SP1600, Leica Microsystems, Wetzlar, Germany), histological sections (10-20 $\mu \mathrm{m}$ thick) were made along the plane perpendicular to the orbital floor. The tissue samples of the intramuscularly implanted materials were sawed parallel to the long axis of the implants. Sections for light microscopy (Nikon Eclipse E200, www.nikon. com) observation were stained with $1 \%$ methylene blue (Sigma-Aldrich, The Netherlands) and $0.3 \%$ basic fuchsin (Sigma-Aldrich) solutions. Sections for epifluorescent confocal laser microscopy (Leica TCS SP2, Leica, Wetzlar, Germany) observation were not stained. Epifluorescent data were collected with $20 \mathrm{x}$ oil immersion objective, including transmitted light detection. The peak absorption (abs.) and emission (em.) wavelengths were: $351 / 364 \mathrm{~nm}$ abs. and $560 \mathrm{~nm}$ em., $543 \mathrm{~nm}$ abs. and $580 \mathrm{~nm}$ em., $488 \mathrm{~nm}$ abs. and $517 \mathrm{~nm}$ em., for Tetracycline, Xylenol Orange 
and Calcein, respectively. These are the optimal settings. This means that, contrary to conventional fluorescent microscopy, the fluorescence colours of Oxytetracycline, Xylenol Orange and Calcein are blue, red and green, respectively. (Note that these settings also allow us to distinguish between the fluorescence of Tetracycline in blue and the co-localisation of Xylenol Orange and Calcein in yellow.

\section{Histomorphometry and statistics}

Images of the stained sections for histomorphometric analysis were made using a slide scanner (Dimage Scan Elite 5400 II, Konica Minolta Photo Imaging, www. konicaminolta.com). Histomorphometry was performed using Adobe Photoshop Elements 4.0 software (Adobe, San Jose, CA, USA). From each animal, multiple sections were prepared for histomorphometric analysis. However, from each obtained explanted sample one section was prepared for histomorphometrical analysis. The prepared sections were taken from the centre of the implantations. Briefly, the implant area was selected as the region of interest (ROI) and the corresponding number of pixels registered. Then, both BCP particles and mineralised bone were pseudo-coloured and the resulting numbers of pixels used to calculate the percentage of bone formation in the available space (available space is defined as the space between the BCP particles assuming the polymer has resorbed) as:

$$
\text { Boneformation } \%=\frac{\text { Bonepixels }}{R O I-\text { BCPpixels }} \times 100 \%
$$

Averages and standard deviations were calculated for the percentage of bone formed in the available area.

\section{Radiological examination}

Cone-beam computed tomography (CBCT) scanning was performed preoperatively to assess the position of the orbital floor. The position of the reconstructed orbital floor was assessed postoperatively and at the time of termination. Scanning was carried out under general anaesthesia with propofol $(1.5 \mathrm{mg} / \mathrm{kg})$. The CBCT images were acquired with an i-CAT Scanner (i-CAT, Imaging Sciences International, Hatfield, PA, USA) with a $0.3 \mathrm{~mm}$ voxel size and a $170 \mathrm{~mm}$ field of view. Each scan was performed with the head of the animal in the same, reproducible position using the laser guide of the scanner as a reference.

Using Mimics Software (Materialise Dental, Leuven, Belgium), 3-dimensional (3D) reconstructions of all individual scans were made. In each dataset, a threshold was applied to depict the bone. The preoperative (intact) orbital floors, and the postoperative reconstructed orbital floors (i.e., the orbital floor implants) and the reconstructed orbital floors at the time of termination, were then selected as region of interest (ROI). Using Geomagic Studio Software (Geomagic, Rock Hill, SC, USA), the $3 \mathrm{D}$ reconstructed scans were aligned and registered with the preoperative $3 \mathrm{D}$ reconstructed scans using an iterative closest-point registration algorithm. The deviations between the datasets are presented using a sliding colour scale to visualise the differences between the surfaces of the orbital floors at the different time points (see for example Fig. 7). For each implant, the mean negative deformation at the location of the defect was calculated.

The negative deformation of the different implants at the different time points was used to calculate the increase of the orbital volume using (Van Leeuwen et al., 2012a):

$$
V_{\text {increase }}=\frac{1}{6} \pi h\left(3 r^{2}+h^{2}\right)
$$

where

- $\quad V_{\text {increase }}=$ volume increase of the orbital cavity due to deformation of the reconstruction material $\left(\mathrm{m}^{3}\right)$.

- $h=$ deformation of the disk-shaped implant $(m)$.

- $r=0.0098(\mathrm{~m})$; this is the radius of a circular orbital floor defect measuring $3.0 \mathrm{~cm}^{2}$.

The changes in orbital volume give an indication of the suitability of the different implants for reconstruction of orbital floor defects in sheep. An increase in orbital volume of no more than $0.7 \mathrm{~cm}^{3}$ is considered the maximum allowable volume increase, as a larger increase in volume can lead to enophthalmos (Ploder et al., 2002; Van Leeuwen et al., 2012a).

\section{Results}

During the in vivo experiment, none of the sheep showed signs of infection or adverse tissue reactions. One (otherwise healthy) animal died unexpectedly 6 months postoperatively. A performed autopsy did not reveal an obvious cause of death. No animals were excluded from this study, and the prematurely deceased animal was evaluated as a separate 6-month time point group.

\section{Descriptive microscopy of intramuscular implantations}

After 3 and 9 months, all intramuscularly implanted specimens were harvested. Table 2 gives an overview of the bone incidence observed. Light microscopical evaluation of the stained sections showed that bone formation had occurred when BCP particles or BCP-containing materials were implanted. Implantations of PTMC sheets that did not contain BCP particles did not lead to formation of bone in any of the sheep.

Fig. 1 gives an overview of the intramuscularly implanted materials after 3 months. Light microscope observations showed that, when present, bone had formed around the BCP particles. The BCP particles were in close contact with the newly formed bone. Ingrowth of connective tissue was also observed. It was shown that for the implanted PTMC/BCP composites the PTMC polymer matrix had degraded profoundly and only small amounts of the polymer could be identified. Of the laminated PTMC/ BCP-PDLLA composite, the PDLLA component could still be seen at this time point. In the implantations of the PTMC sheets (not containing BCP) no bone was formed. The remaining PTMC was surrounded by a fibrous capsule of dense connective tissue. Besides signs of polymer degradation, also disintegration of the $\mathrm{BCP}$ particles was 
Table 2: Bone incidence upon implantations after 3, 6 and 9 months and concomitant percentages of the amount of new bone formed in the available area as determined by histomorphometry. Mean \pm SD is presented.

\begin{tabular}{|l|c|c|c|c|c|c|}
\hline Implanted material & $\begin{array}{c}\text { Bone incidence } \\
\mathbf{3} \text { months }\end{array}$ & \% new bone & $\begin{array}{c}\text { Bone incidence } \\
\text { 6 months }\end{array}$ & \% new bone & $\begin{array}{c}\text { Bone incidence } \\
\text { 9 months }\end{array}$ & \% new bone \\
\hline BCP particles & IM: $2 / 5$ & $2.9 \pm 5.9$ & IM: $1 / 1$ & 12.8 & IM: $2 / 4$ & $6.4 \pm 6.9$ \\
\hline \multirow{2}{*}{ PTMC } & OF: $0 / 3$ & $0 \pm 0$ & NI & & OF: $0 / 3$ & $0 \pm 0$ \\
& IM: $0 / 3$ & $0 \pm 0$ & NI & & IM: $0 / 3$ & 0 \\
\hline PTMC/BCP composite & OF: $3 / 4$ & $7.7 \pm 8.1$ & OF: $1 / 1$ & 14.9 & OF: $3 / 3$ & $15.7 \pm 14.6$ \\
& IM: $2 / 4$ & $0.3 \pm 0.6$ & IM: $0 / 1$ & 0 & IM: $0 / 3$ & 0 \\
\hline PTMC/BCP-PDLLA & OF: $3 / 3$ & $5.3 \pm 4.0$ & OF: $1 / 1$ & 13.9 & OF: $1 / 2$ & $1.7 \pm 2.4$ \\
laminated composite & IM: $2 / 3$ & $2.0 \pm 1.9$ & IM: $0 / 1$ & 0 & IM: $0 / 2$ & 0 \\
\hline
\end{tabular}

OF: orbital floor

IM: intramuscular

NI: not implanted

observed. In Fig. 2 the degradation of the polymeric PTMC matrix and the disintegration of the $\mathrm{BCP}$ particles is shown at higher magnifications. The highest magnifications showed the recruitment of phagocytic and multi-nucleated giant cells. These cells adhered to the surface of remnants of PTMC polymer and to the BCP particles.

Histological images of the intramuscularly implanted materials at 9 months are available as supplementary information. After 9 months, the implantation of the BCP particles had led to progressive bone formation. By contrast, ectopically formed bone upon implantation of the PTMC/BCP composites and the PTMC/BCP-PDLLA laminated composite could not be discerned at this time point. The polymeric components of the composites had resorbed almost completely. Only few phagocytosed PTMC particles could be observed. Signs of disintegration of the BCP particles were seen. The intramuscularly implanted PTMC sheets were still identifiable, although degradation had progressed. The remaining material was surrounded by a fibrous capsule consisting of dense connective tissue.

\section{Descriptive microscopy of the orbital implantations}

The results of the evaluations of the orbital implantations are shown in Table 2 and Fig. 3. After 3 months, the composite implants and the laminated composites clearly showed the formation of bone. Most of the polymeric PTMC matrix had degraded at this time, and only small remnants of the polymer could be observed. The newly formed bone was in close contact to the BCP particles that had now become available. Following the implantation of the composite implants, the newly formed bone showed osseous integration with the host bone at places where the implants were in contact with the host bone (i.e., at the orbital floor defect borders), see Fig. 4. At the site of the defect, where the composite implants were not in contact with host bone, several layers of dense connective tissue covered the degrading implants. However, bone had also formed in regions where the implant covered the defect; this is shown in Fig. 3B and $3 \mathrm{H}$.

The PTMC/BCP-PDLLA laminated composites, by contrast, did not show this osseous integration of newly formed bone with host bone. These were completely surrounded by a fibrous capsule composed of dense connective tissue (Fig. 4).
After 9 months, the bone formation appeared to be progressive for the $\mathrm{PTMC} / \mathrm{BCP}$ composite implants. In some animals, bone almost bridged the defect (Fig. 3H). Both the PTMC/BCP composite implants and the PTMC/ BCP-PDLLA laminated composite implants showed almost complete resorption of the polymeric PTMC matrix. Only some remaining phagocytosed PTMC polymer material could be discerned. The PDLLA layer seemed to have been resorbed completely at 9 months. Whereas the newly formed bone in the composite implants still showed integration with the host bone at this time point, the PTMC/ BCP-PDLLA laminated composites remained surrounded by a fibrous capsule and subsequently did not show osseous integration.

Signs of disintegration of the BCP particles were also seen after the 9-month implantation period. Fig. 5 shows a PTMC/BCP composite implant and a PTMC/BCP-PDLLA laminated composite implant after 3 and 9 months at higher magnifications.

The histological findings for the animal that died after 6 months were comparable to the observations found for the other animals after 9 months. In this animal, the orbital PTMC/BCP composite implant showed new bone formation that had integrated with the host bone. Although the PTMC/BCP-PDLLA laminated composite implant placed in the other orbit did show bone formation, the newly formed bone (again) had not integrated with the host bone. A fibrous capsule surrounded the laminated composite implant. Besides the intramuscularly implanted BCP particles, none of the intramuscular composite material implantations lead to ectopic bone formation (see Table 2). At 6 months the degradation and resorption of the PTMC polymer matrix and the PDLLA layer was shown to be progressive when compared to 3-month implants. However, the degradation was not as advanced as in the 9-month groups. Remnants of the PDLLA layer could still be identified. Disintegration of the BCP particles was observed when BCP or (laminated) BCP composites were implanted.

\section{Fluorescence microscopy}

Epifluorescent confocal microscopy of the sequential fluorochrome labels revealed that 3 weeks after implantation the formation of bone had started in the intramuscular implantations of the BCP particles and 

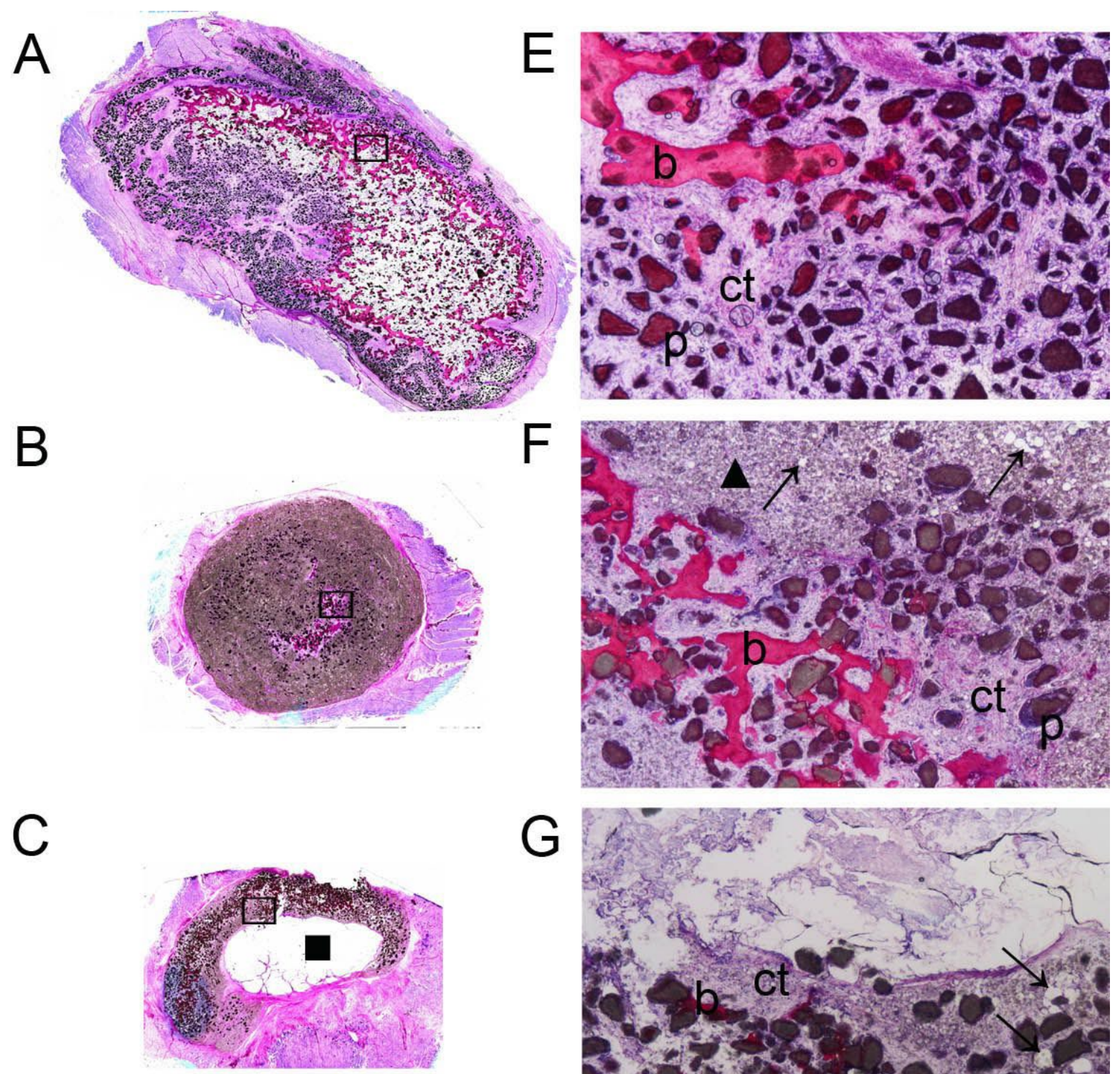

G
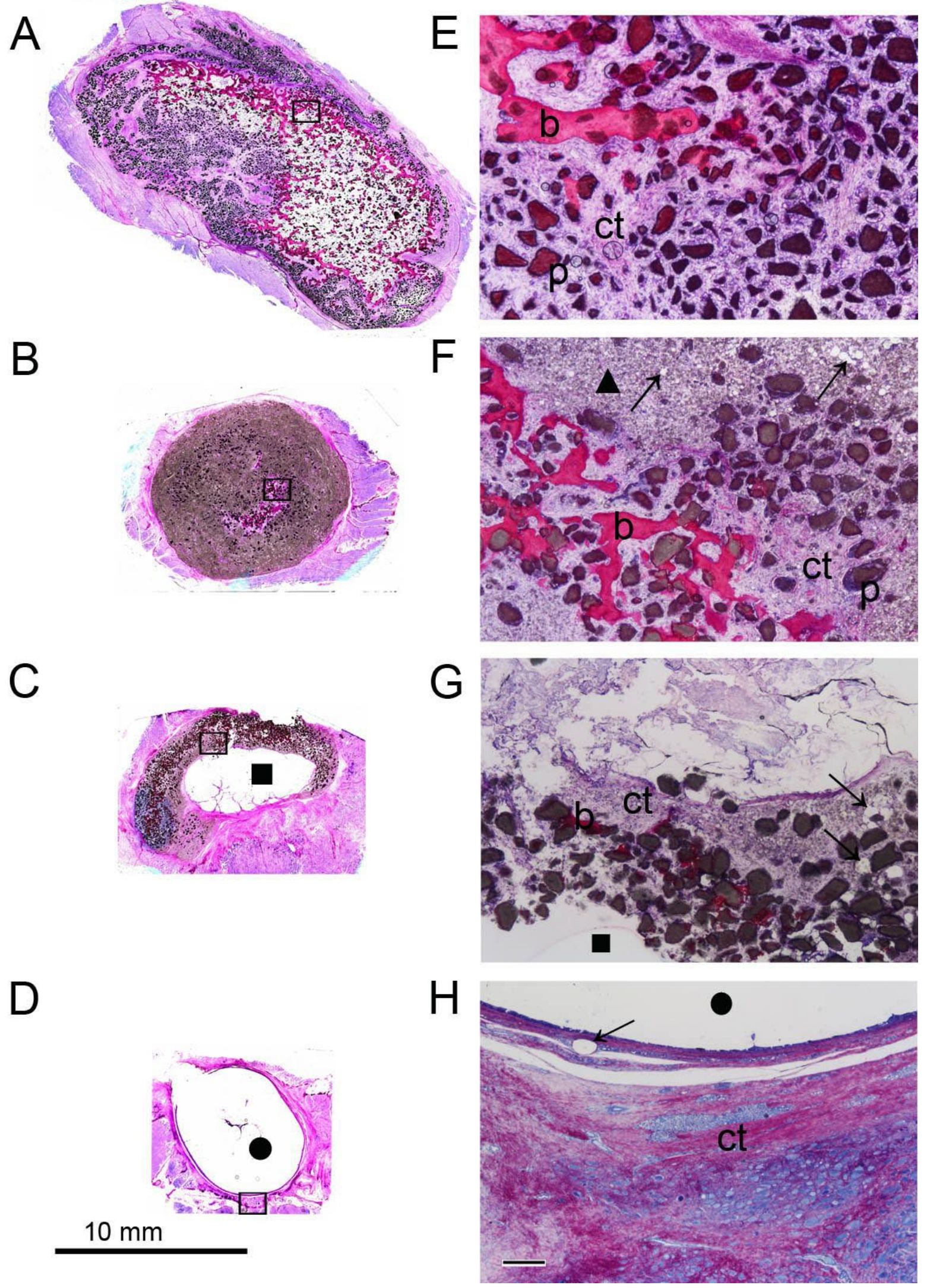

Fig. 1. Light micrographs of intramuscular implantation sites after 3 months. A-D represent overviews of intramuscular implantations of respectively BCP, PTMC/BCP composite, PTMC/BCP-PDLLA laminated composite and PTMC. $\mathbf{E}-\mathbf{F}$ represent magnifications $(4 \mathrm{x})$ of the corresponding marked regions: image $\mathbf{E}$ is a magnification of $\mathbf{A}$, image $\mathbf{F}$ of $\mathbf{B}$, etc. Bone (b) is clearly visible and surrounds the BCP particles (p) in Figs. $\mathbf{1} \mathbf{A}-\mathbf{C}$ and their corresponding magnifications. The PTMC (•) matrix has degraded, however still phagocytosed polymeric material (arrows) can be observed. ( $\mathbf{\Delta}$ ) designates an area where remnants of disintegrated BCP particles are present. ( $\mathbf{\square})$ PDLLA polymer. (Scale bar represents $100 \mu \mathrm{m}$ ). Note that the polymer is transparent in the microscopical sections, and thus shows white in the images. 

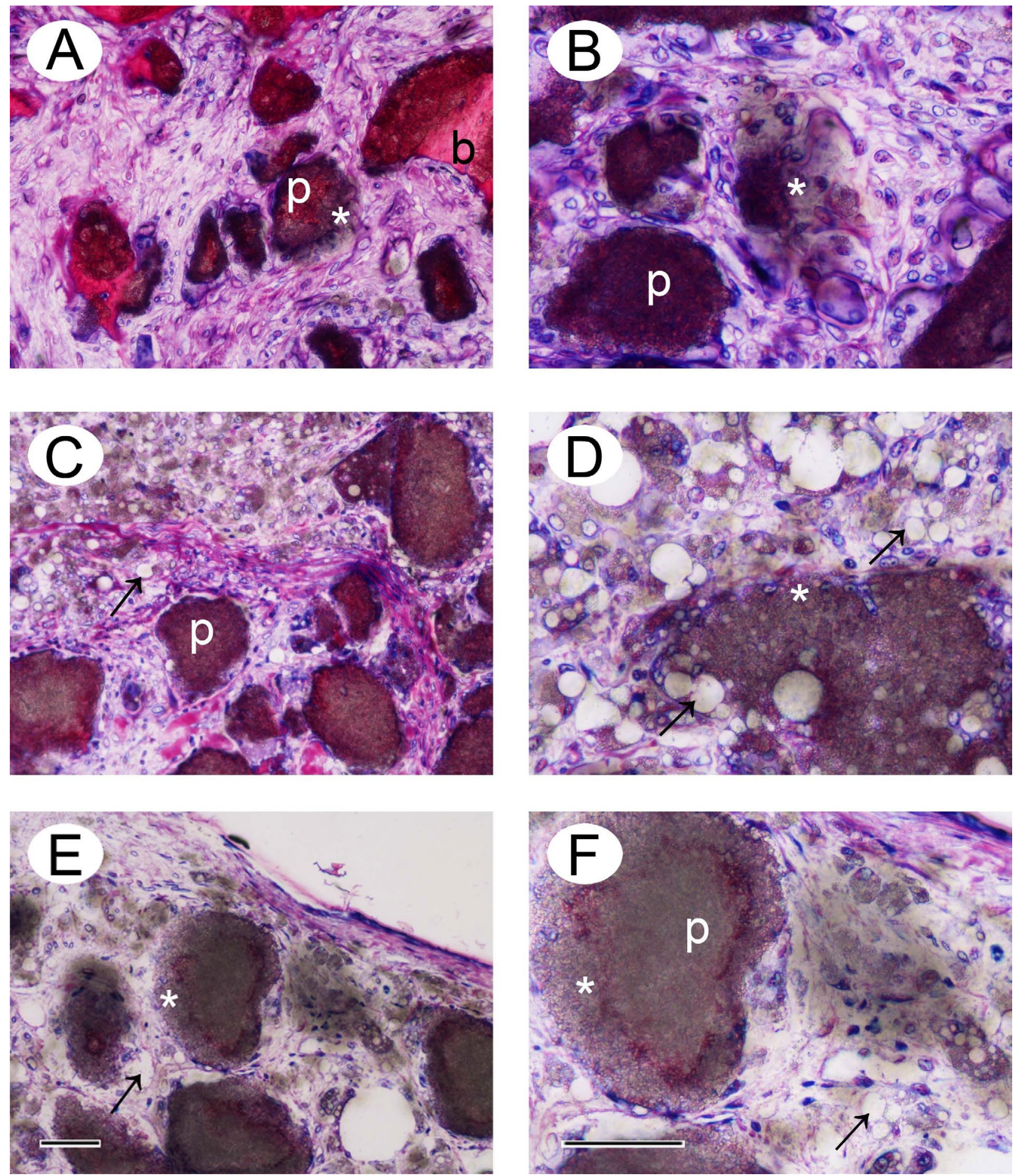

Fig. 2. Light micrographs of intramuscular implantations after 3 months of respectively pure BCP particles (A, B), PTMC/BCP composite $(\mathbf{C}, \mathbf{D})$ and PTMC/BCP-PDLLA laminated composite $(\mathbf{E}, \mathbf{F})$. BCP particles are surrounded by phagocytic cells. The dust-like aspect $\left(_{*}\right)$ at the surface of the particles (p) suggests their disintegration. Remaining PTMC material (indicated by the arrows) can clearly be identified. (b) bone. (Figs. 2A, C and $\mathbf{E}$ are 20x magnifications, Figs. 2B, D and F 40x). (Scale bars represent $50 \mu \mathrm{m}$ ).

the (laminated) composites. Similar observations were found for the PTMC/BCP composite and the laminated PTMC/BCP-PDLLA composite implants in the orbital implantation experiments (Fig. 6). Colours for the labels were set as follows: calcein is green; xylenol orange is red; oxytetracycline is blue. Analysis of the fluorochrome labels indicated that the formation of bone had started at the surface of the BCP particles and progressed outwards.
After 9 months, the fluorochrome labelling showed that the process of bone formation and remodelling was still active in the orbital floor implantations. None of the intramuscularly implanted (laminated) composites showed fluorescence after 9 months. The prematurely deceased animal had died before the fluorochromes were administered and did therefore not show fluorochrome fluorescence. 

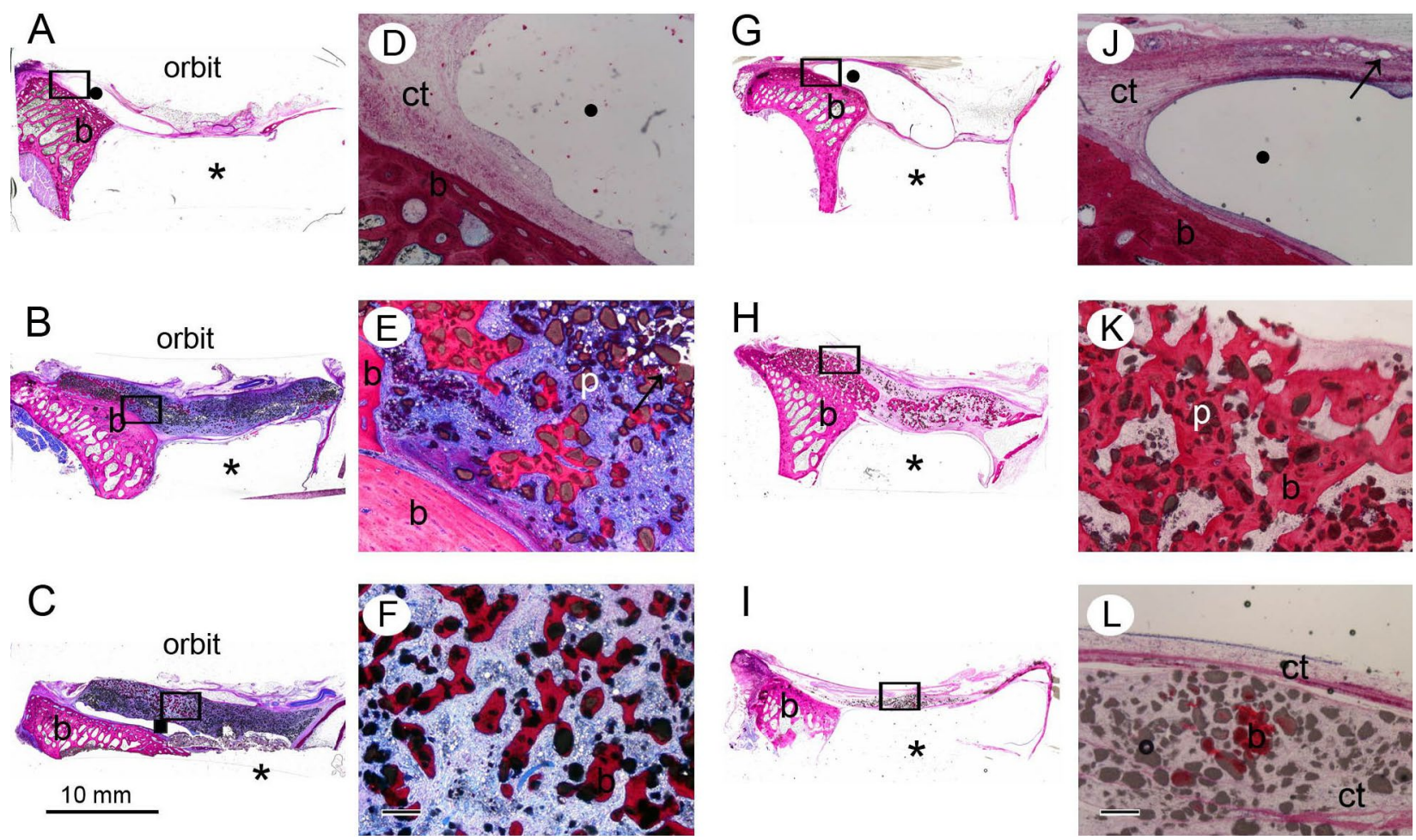

Fig. 3. Light micrographs of orbital implantations after 3 (A-F) and 9 (G-L) months. D, $\mathbf{G}$ and $\mathbf{J}$ show reconstruction with the PTMC sheet. Capsule formation is visible (see CT area in images $\mathbf{D}$ and $\mathbf{J}$ ), there is no sign of bone formation. New bone formation is clearly visible and in close contact with the BCP particles after 3 months in the PTMC/BCP composite sheet $(\mathbf{B}, \mathbf{E})$ and is progressive after 9 months $(\mathbf{H}, \mathbf{K})$. Note that bone is growing in/over the original defect area in $\mathbf{H}$. The PTMC/BCP-PDLLA laminated composite sheet also showed bone formation around BCP particles after 3 months $(\mathbf{C}, \mathbf{F})$, however to a lesser extent than when compared to the composite sheet as shown in image $\mathbf{B}$,

$\mathbf{E}, \mathbf{H}$ and $\mathrm{K}$. After 9 months limited bone formation was found as shown in image $\mathbf{I}$ and $\mathbf{L}$.

Images D-F and $\mathbf{J}-\mathbf{L}$ are $4 \mathrm{x}$ magnifications of respectively the corresponding marked regions in images A-C and $\mathbf{G}-\mathbf{I}$; (•) PTMC, (*) maxillary sinus, (b) bone, (p) BCP particle, (घ) PDLLA polymer, (arrow) residual polymeric PTMC material, (ct) connective tissue. (Scale bar represents $100 \mu \mathrm{m}$.).

\section{Histomorphometry}

The results of the histomorphometrical analysis of the intramuscular and orbital implantation sites are shown in Table 2. The mean percentages and standard deviations are presented for the amount of bone formed in the available area. (The available area is defined as the space between the BCP particles where the polymer has resorbed). Not all animals showed bone formation following the implantations. Furthermore, when bone was present, large variations in the amounts of formed bone were observed in and between individual animals.

After 3 months, measurements showed $7.7 \pm 8.1 \%$ (mean $\pm \mathrm{SD}$ ) of bone had formed following the PTMC/ BCP composite orbital floor implantations. After 9 months, the percentage of bone had increased to $15.5 \pm 12.0 \%$. The PTMC/BCP-PDLLA laminated composite orbital floor implants showed $5.3 \pm 4.0 \%$ and $1.7 \pm 2.4 \%$ of bone formation, respectively after 3 and 9 months. The intramuscular implantations only showed limited bone formation. The intramuscularly placed PTMC/BCP composite samples showed $0.3 \pm 0.6 \%$ and the PTMC/ BCP-PDLLA laminated composite $2.0 \pm 1.9 \%$ of bone formation after 3 months. The intramuscularly placed amounts of BCP particles showed $2.9 \pm 5.9 \%$ bone formation, which progressed to $6.4 \pm 6.9 \%$ of bone after 9 months.

The prematurely deceased animal showed respectively $13.9 \%$ and $14.9 \%$ of bone formation for the PTMC/BCPPDLLA laminated composite and PTMC/BCP composite implantations in the orbits. The intramuscularly implanted $\mathrm{BCP}$ particles resulted in $12.8 \%$ bone formation.

\section{Evaluation of the reconstructed orbital floor by cone beam CT (CBCT)}

Fig. 7 graphically presents the evaluation process of the reconstruction of the orbital floors, and illustrates the performance of the different implants. It can be seen that the radio-opaque PTMC/BCP composite and PTMC/ BCP-PDLLA laminated composite sheets were easily identified. As described in the experimental part, the colour mapping shows the deviation of the reconstructed orbital floor compared to the preoperative intact orbital floor. The results for the deformation of the implants and the calculated changes in the concomitant orbital volumes are summarised in Table 3. It can be seen that the increase in the orbital volume of animals treated with the PTMC implants (implants not containing BCP) ranged from +0.16 to $+0.23 \mathrm{~cm}^{3}$, after 3 and 9 months respectively. The 

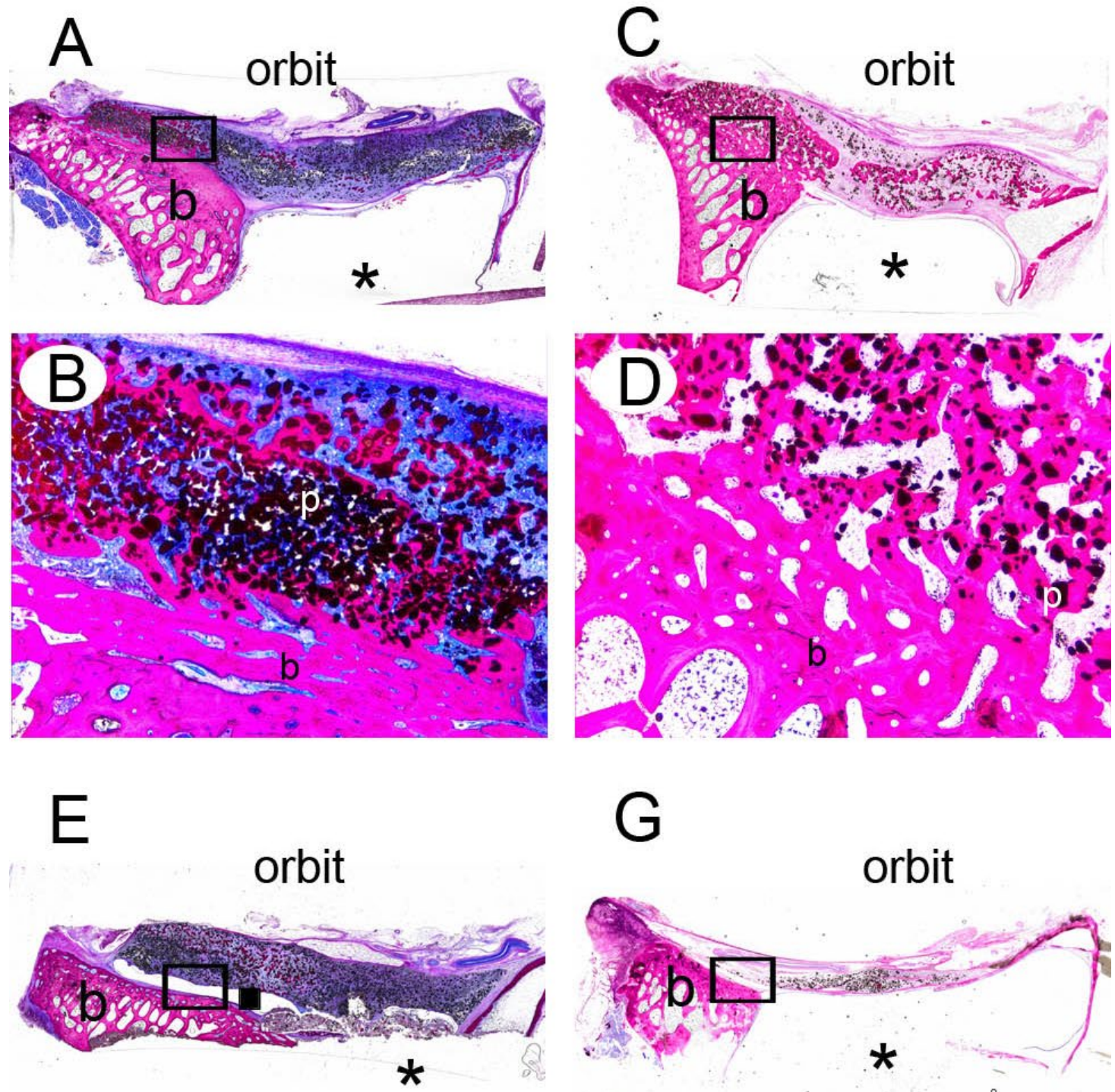

G

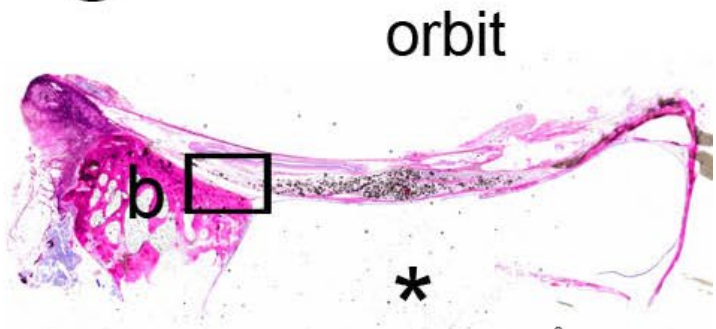

\section{$10 \mathrm{~mm}$}
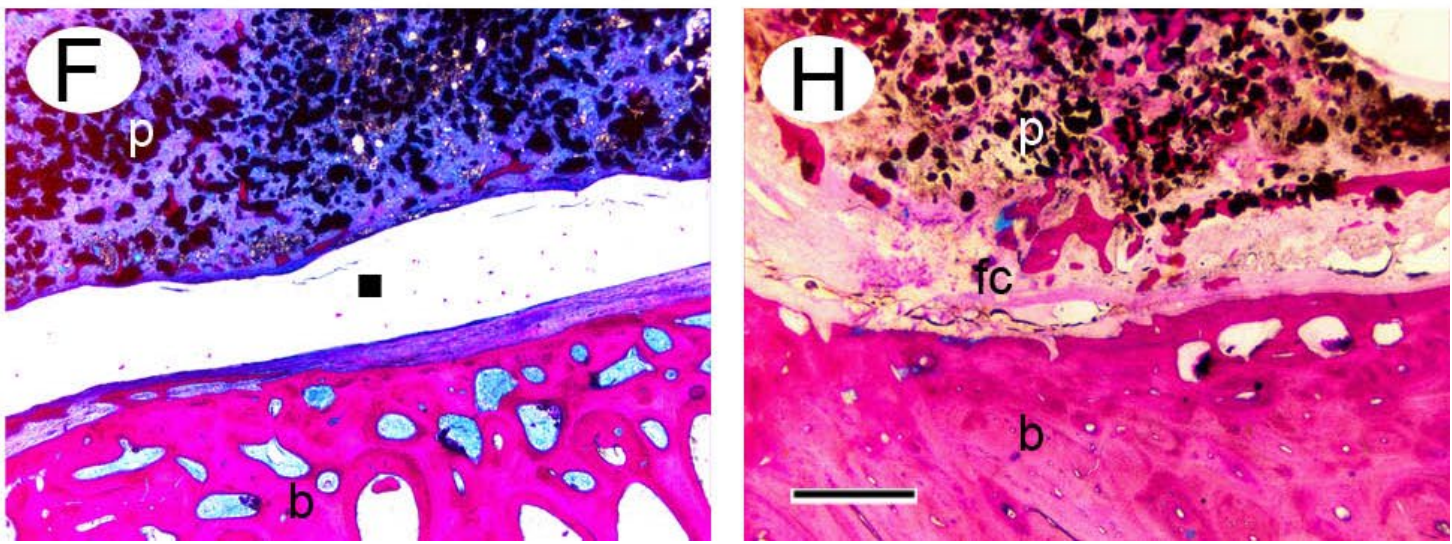

Fig. 4: Light micrographs $(2.5 \mathrm{x})$ representing the transition area of the PTMC/BCP composite (A-D) and the PTMC/ BCP-PDLLA laminated composite (E-H) implant, to host (and newly formed) bone in the orbit of the sheep. B and D are respectively magnifications of the marked areas shown in $\mathbf{A}$ and $\mathbf{C}$ where the composite implants are in close contact with the host bone and show excellent osseous integration of newly formed bone with the host bone after respectively 3 and 9 months. $\mathbf{F}$ and $\mathbf{H}$ are respectively magnifications of the areas shown in $\mathbf{E}$ and $\mathbf{G}$ where the laminated composite implants are in close contact with the host bone. F clearly illustrates the PDLLA layer of the laminated composite impeding osseous integration after 3 months. H shows that after 9 months, although the PDLLA layer has degraded, osseous integration of newly formed bone with the host bone still has not occurred. This could be due to the fibrous capsule that is present between the newly formed bone and the host bone. (b) bone, (p) BCP particle, (घ) PDLLA polymer, (fc) fibrous capsule. (Scale bar represents $400 \mu \mathrm{m}$ ). 

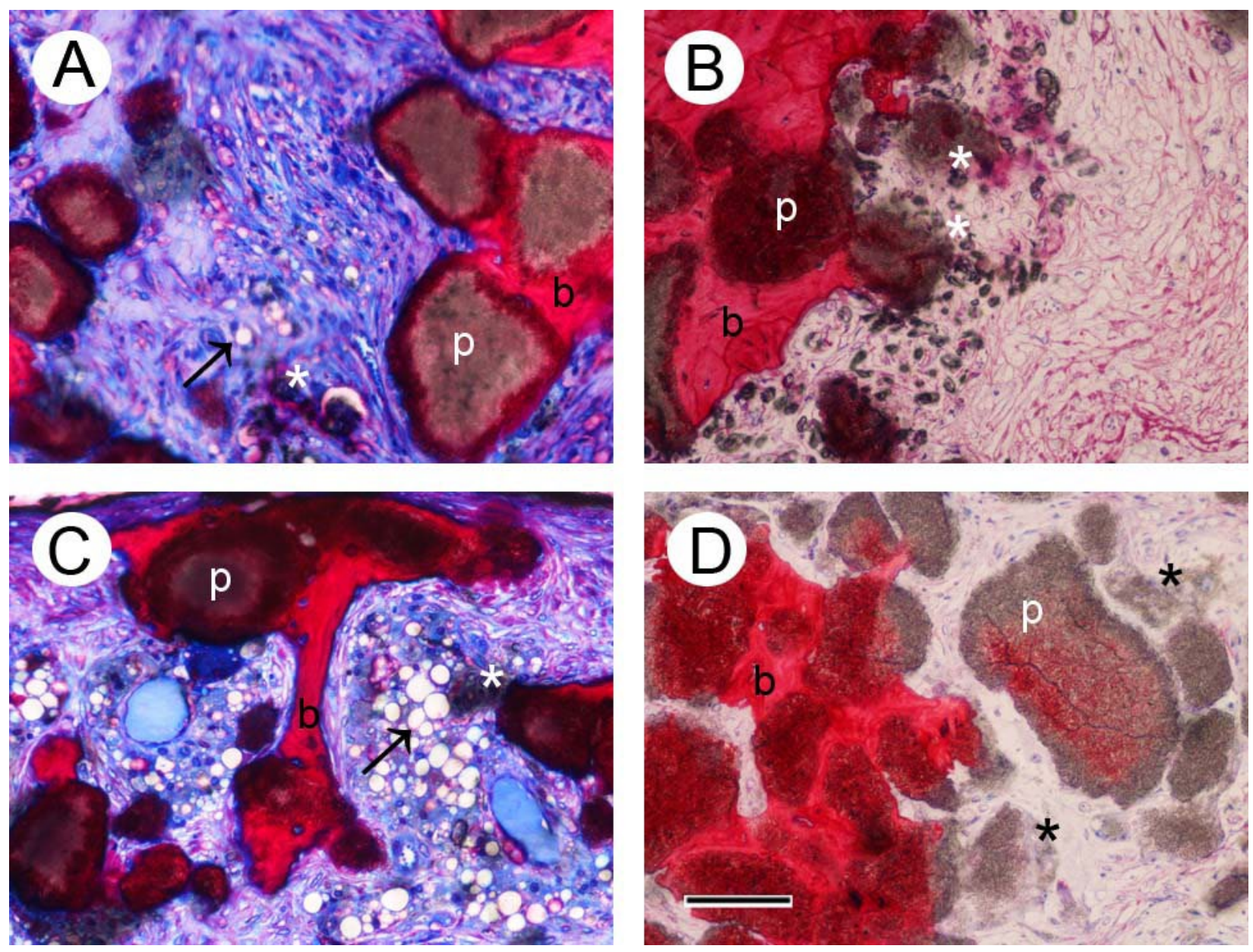

Fig. 5. Light micrographs (20x) showing the disintegration of BCP particles following orbital implantations after 3 and 9 months, respectively. $\mathbf{A}$ and $\mathbf{B}$ are sections of orbital PTMC/BCP composite implantations. $\mathbf{C}$ and D are sections of orbital PTMC/BCP-PDLLA laminated composite implants. The dust-like aspect $\left(_{*}\right)$ at the surface of the BCP particles (p) suggests they are disintegrating. Remaining PTMC material (arrows) is easily identified. The disintegration of the BCP particles in the composite and in the laminated composite tended to be more extensive when compared to the disintegration in the intramuscular implantations of BCP particles only. ( $\left.{ }_{*}\right)$ shows an area containing disintegrating BCP, (arrow) phagocytosed PTMC material, (b) bone. (Scale bar represents $50 \mu \mathrm{m}$.).

Table 3: Mean negative deformations of the reconstructed orbital floors and after 3 and 9 months using different implant materials. The animal that died after 6 months is considered individually. The preoperative scan served as reference. Mean negative deformations $\pm \mathrm{SD}$ are given in $\mathrm{mm}$.

The calculated increase in volume after 3,6 and 9 months for the different reconstruction materials is also provided. Mean negative deformations $\pm \mathrm{SD}$ are given in $\mathrm{cm}^{3}$. The increase in volume occurred due to deformation of the reconstruction materials. The defect size was considered to be $3 \mathrm{~cm}^{2}$.

\begin{tabular}{|l|c|c|c|c|c|c|c|c|}
\hline & $\begin{array}{c}\text { PTMC } \\
\text { 3 months }\end{array}$ & 9 months & $\begin{array}{c}\text { PTMC/BCP* } \\
\text { 3 months }\end{array}$ & 6 months & 9 months & $\begin{array}{c}\text { PTMC/BCP-PDLLA** } \\
\text { 3 months }\end{array}$ & 6 months & 9 months \\
\hline Deformation (mm) & $-0.77 \pm 0.25$ & $-1.20 \pm 0.36$ & $-0.48 \pm 0.79$ & -1.1 & $-0.67 \pm 0.25$ & $-0.80 \pm 0.26$ & -0.7 & $-0.70 \pm 0.42$ \\
\hline Vol. increase orbit $\left(\mathbf{c m}^{\mathbf{3}}\right)$ & $0.12 \pm 0.04$ & $0.18 \pm 0.06$ & $0.10 \pm 0.08$ & 0.16 & $0.10 \pm 0.04$ & $0.13 \pm 0.04$ & 0.11 & $0.11 \pm 0.07$ \\
\hline
\end{tabular}

* PTMC/BCP: composite

** PTMC/BCP-PDLLA: laminated composite 
Fig. 6. Epifluorescent confocal micrographs of intramuscularly implanted BCP (A-B) and PTMC/ BCP composite $(\mathbf{C}-\mathbf{D})$. E-F and $\mathbf{G}-\mathbf{H}$ are images of orbital implantations of the PTMC/BCP composite after, respectively 3 and 9 months. A, $\mathbf{C}, \mathbf{E}$ and $\mathbf{G}$ are bright field images, B, D, $\mathbf{F}$ and $\mathbf{H}$ are corresponding epifluorescent images. By comparing micrographs of the same region of an unstained section under epifluorescent (B, D, F and H) and transmitted light (A, $\mathbf{C}, \mathbf{E}$ and $\mathbf{G})$, correlations between the composite and bone formation are possible. Calcein $(\mathrm{C})=$ green, Xylenol Orange $(\mathrm{XO})=$ red and Oxytetracycline $(\mathrm{T})=$ blue . It can be seen that bone formation had started after 3 weeks (green coloured zones) around the intramuscularly implanted $\mathrm{BCP}$ and $\mathrm{PTMC} / \mathrm{BCP}$ composite. The orbital implantations showed similar results. Bone formation had started after 3 weeks (green coloured zones in $\mathbf{E - F}$ ) in the 3-month group. The blue coloured zones in $\mathbf{G}-\mathbf{H}$ show the process of bone formation still being active at 9 months.
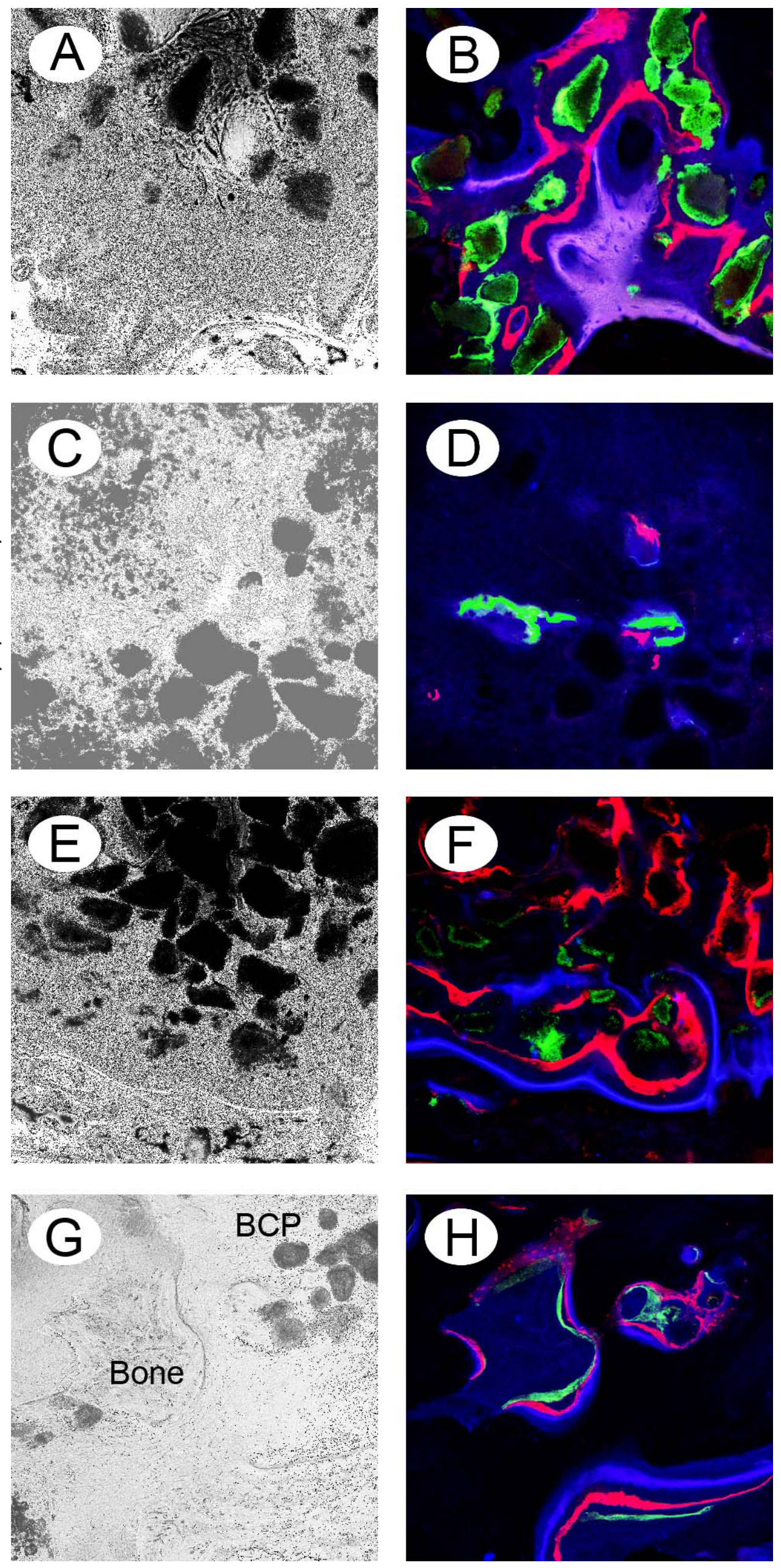

www.ecmjournal.org 

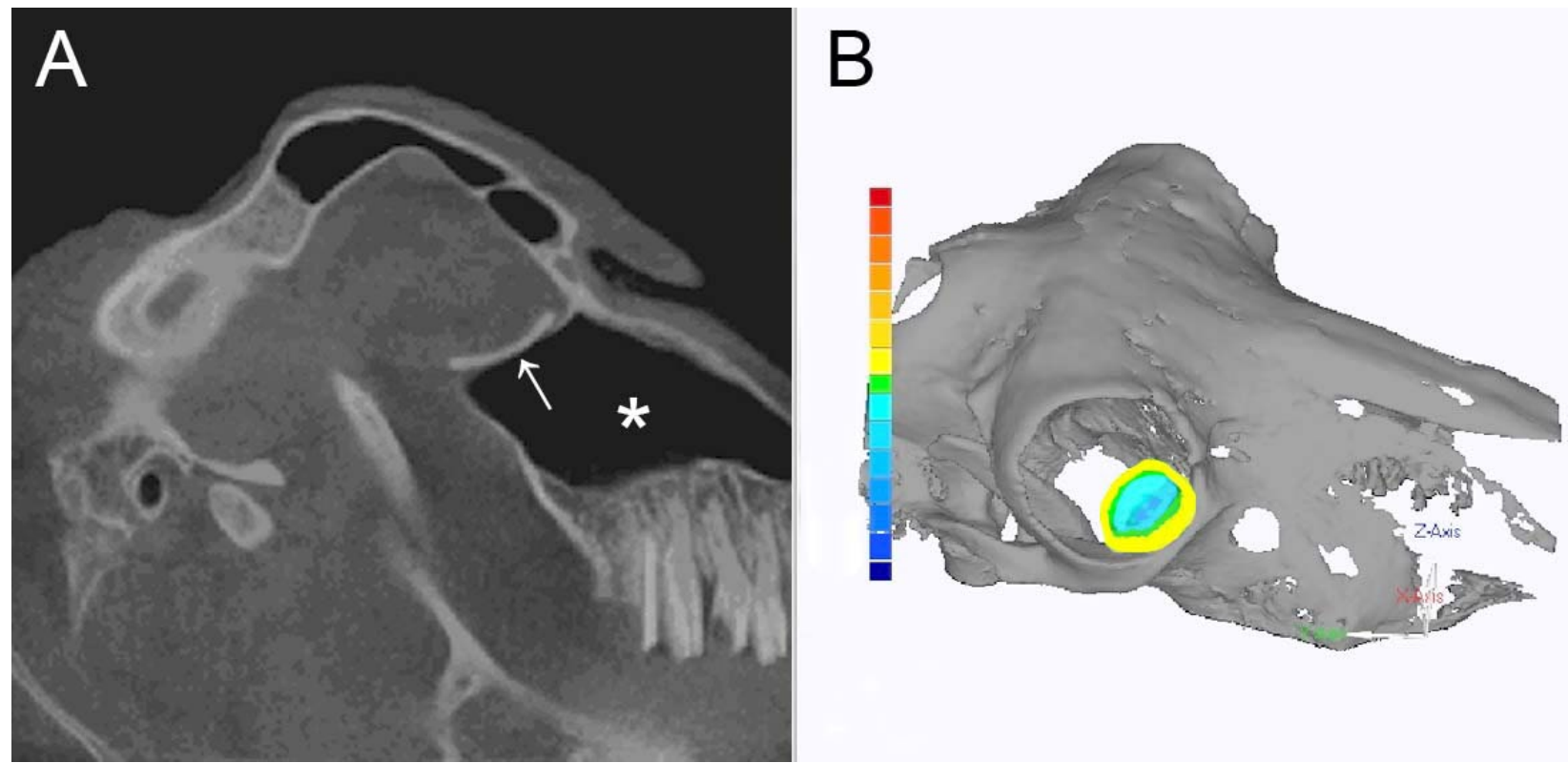

Fig. 7. Assessment of orbital floor position. A shows a lateral view of a postoperative CBCT scan of a sheep. The PTMC/BCP composite implant (arrow) is radio-opaque and can be clearly identified at the top of the maxillary sinus ${ }_{*}$ ). B shows the superposition of the postoperative scan over the preoperative scan. The region of interest is highlighted. The colour mapping is shown. There is a slight 'negative' deformation at the centre of the implant when compared to the preoperative situation. Where the implant overlies the defect borders (i.e. is resting on the intact orbital floor borders), the deformation is slightly 'positive' when compared to the preoperative situation of the intact orbital floor.

animals treated with the PTMC/BCP composite implants showed an orbital volume increase that ranged from +0.14 to $+0.19 \mathrm{~cm}^{3}$, while the animals treated with the PTMC/ BCP-PDLLA laminated composite implants showed volume increases ranging from +0.11 to $+0.15 \mathrm{~cm}^{3}$.

\section{Discussion}

The present study describes the evaluation of the osteoinductive properties of composite materials prepared from PTMC and microstructured BCP. The composite materials were evaluated both in an orthotopic (orbit), as well as in an ectopic (intramuscular) site in sheep. The sheep model is well known and has been thoroughly evaluated (Kontio et al., 2004). With the evaluation of the osteoinductive properties of the composite materials, the suitability of the composite materials to serve as a load-bearing material for orbital floor reconstruction was assessed. From the results of this first study, it seems that PTMC/BCP composite materials and PDLLA-laminated $\mathrm{PTMC} / \mathrm{BCP}$ composite materials have osteoinductive properties and can therefore be suited for use in the reconstruction of critical size orbital floor defects in sheep. Moreover, fluorochrome labelling indicates new bone formation that could be the result of osteoinductivity and or remodelling processes.

To our knowledge this is not only the first report on the in vivo evaluation of osteoinductive solid composites composed of a continuous PTMC phase and a dispersed (biphasic) calcium phosphate particle phase, but it is also the first report on synthetic resorbable osteoinductive composites for use in orbital floor reconstruction.
The first clinical use of resorbable polymeric implants in the management of orbital floor fractures was reported by Cutright and Hunsuck (1972), who used poly(lactic acid) implants to reconstruct orbital floor fractures. Since then, several studies evaluating poly(lactic acid) as a reconstruction material in orbital floor fractures have been conducted (Rozema et al., 1990; Bergsma et al., 1994; Kontio et al., 2004; Baino, 2011).

In the early 1970 s, calcium phosphates were also used to repair bone defects in craniomaxillofacial surgery (Levitt et al., 1969, Monroe et al., 1971). Although their use led to bony regeneration of the fractured orbital floor (Mathur et al., 2003, Sinikovic et al., 2007), problems regarding the shaping of the brittle calcium phosphate implants were encountered. This led to postoperative enophthalmos in a significant number of patients (Nam et al., 2006).

Downes and Tanner (Tanner et al., 1994) reported on an osteoconductive composite for the treatment of orbital floor fractures that was based on hydroxyapatite and polyethylene (HAPEX). This composite did demonstrate neither osteoinductive properties nor signs of degradation. In addition, the limitations of ceramic materials regarding shape-ability were recognised, in particular in the reconstruction of orbital floor fractures.

During the surgical procedures in our study, it became clear that the shape-ability of the PTMC implants was excellent. In addition, the PTMC composite and laminated composite implants were relatively flexible and not brittle at all, and could be easily cut into a desired shape. Furthermore, our results showed that both the composite and the laminated composite implants exerted osteoinductive properties. The composite implants showed excellent osseous integration of the newly formed bone 
with the host bone. At the defect site, where the composite implants were not in contact with host bone, even new bone formation that almost bridged the defect was demonstrated. Although such findings have been reported previously (Rozema et al., 1990; Kontio et al., 2004) this is nevertheless of great importance for the long-term results as the composite implants are resorbable and bony regeneration of the orbital floor at the defect site is the main target.

The histological observations of the degradation of the polymeric PTMC matrix with simultaneous formation of bone supported our hypothesis that a resorbable polymeric matrix could enhance the mechanical properties of calcium phosphate ceramics, without negatively affecting the osteoinductive properties of the calcium phosphate particles. For the laminated composites, however, the PDLLA layer might have exerted a negative effect on bone formation and osseous integration of newly formed bone with host bone in two ways: firstly, by creating a physicomechanical barrier between the composite and host bone and secondly, by inducing an acidic environment during degradation which can have detrimental effects on host bone and bone formation (Taylor et al., 1994; Wu and Ding, 2004).

Osseous integration might also have been impeded by the fibrous capsule, which surrounded the degrading laminated composites. Formation of a fibrous capsule around (resorbable) biomaterials occurs when the surfaceto-volume ratio of the implanted biomaterial is unfavourably low, or when the implanted biomaterial impedes or hinders the regeneration of normal tissues (Anderson and Shive, 1997; Ratner et al., 2004)). This could explain the fact that while remnants of the orbitally implanted PTMC/ BCP composite implants were not completely surrounded by a fibrous capsule, remnants of the (orbitally implanted) PTMC/BCP-PDLLA laminated composite implants and the PTMC implants were completely encapsulated. Both the PTMC and the PDLLA layer might have hindered the regeneration of normal tissue. The $\mathrm{PTMC} / \mathrm{BCP}$ composites did not hinder the regeneration of normal/local tissue as their use led to excellent osseous integration. Since the degradation process can progress along the surface of exposed BCP particles, the surface-to-volume ratio can be expected to increase favourably.

The histological observation of the disintegration of $\mathrm{BCP}$ particles (also in composites) has been reported previously (Benahmed et al., 1996; Dupraz et al., 1998; Dupraz et al., 1999; Gauthier et al., 1999; Fellah et al., 2010). Dupraz et al. developed a composite of BCP and a degradable cellulosic ether (Dupraz et al., 1998). The result from their in vivo study in rabbits revealed that phagocytosis upon implantation of the composites and of the BCP particles themselves was mediated by macrophages and giant multinucleated cells. Since these cells play a major role in the degradation process of PTMC (Pego et al., 2003b; Bat et al., 2010) it is most likely that macrophages and giant multinucleated cells also are involved in the BCP disintegration process observed in our experiments.

The large variations in the amounts of induced bone that we observed in and between the individual animals are not uncommon in research on osteoinductive materials. It is known that, besides animal-specific factors, implantation site-specific factors can also have an effect on the amount of induced bone (Habibovic et al., 2006; Yuan et al., 2006a; Yuan et al., 2006b). Implantations in orthotopic locations tend to result in larger amounts of induced bone than implantations in ectopic locations (Habibovic et al., 2006). In addition, it is suggested that the intrinsic ability of individual animals to form new bone in osteopromotive environments could vary as a result of genetic factors which in the process of osteoinduction can lead to different responses (Geesink et al., 1999; Marusic et al., 1999; Habibovic et al., 2005). As we used non-inbred Texel sheep, genetic variation can be expected to be present.

The evaluation by CBCT showed that all the reconstructed orbital floors were adequately positioned as compared with the preoperative anatomical situation. None of the maximum calculated increases in volume of the orbits that result from deformation of the implants were larger than the aforementioned critical value of $0.7 \mathrm{~cm}^{3}$ (see Table 3). In the treatment of orbital floor fractures with resorbable materials, the main short-term goal is to obtain a stiff scar composed of a dense connective tissue capsule. This scar prevents the orbital content from sagging into the maxillary sinus during degradation or resorption of the implant (Enislidis, 2004). It should be noted however, that complications at the long-term (such as late enophthalmos) are not always prevented by the formation of such fibrous capsule, and ideally bone is regenerated at the level of the orbital floor defect. In this respect, the PTMC/BCP composite and PTMC/BCP-PDLLA laminated composite showed promising results. Nonetheless, future research on the outcomes at the long-term will need to be conducted. The question whether the regenerated bone will become a regenerated bony orbital floor that is in contact with the host bone and capable of keeping the orbital content in position and prevent late on-set enophthalmos will be addressed.

\section{Conclusions}

The present study describes the preparation and in vivo evaluation of osteoinductive composites composed of PTMC and microstructured BCP particles for use in orbital floor reconstruction. Composites were also laminated with PDLLA. From the obtained data it can be concluded that the composite materials are shapeable, exert osteoinductive properties and are likely very well suited for use in the bone-regenerating reconstruction of orbital floor fractures in sheep. Furthermore, excellent osseous integration of the newly formed bone with the host bone was observed, after 9 months bone almost bridged the defects reconstructed with the PTMC/BCP composite materials.

Future research focussing on the long-term performance as well as improvement of the osteoinductive properties of these promising composite materials will be performed, and definitive conclusions regarding their bone regenerating capacity and suitability as reconstruction material in the treatment of orbital floor fractures will be drawn. In addition, based on the favourable results of the present 
study, the preparation of other PTMC composites with bone forming-components such as Bioglass, can be considered as well.

\section{Acknowledgements}

Gratitude is expressed to Ms. L. van Leeuwen, Mr. D. Barbieri and Mr. X Luo for their assistance in the animal experiments and histological processing of the explanted samples. Ms. M.B.M. van Leeuwen and Mr. K. van den Broek are acknowledged for their assistance in the fluorochrome labelling process. Furthermore, we thank the department of Oral and Maxillofacial Surgery, Radboud Univertsity Medical Centre Nijmegen, The Netherlands, for their assistance during the post-mortem CBCT scans.

Conflict of interest statement: H. Yuan and J.D. de Bruijn, are shareholders of Xpand Biotechnology.

\section{References}

Anderson JM, Shive MS (1997) Biodegradation and biocompatibility of PLA and PLGA microspheres. Adv Drug Deliv Rev 28: 5-24.

Baino F (2011) Biomaterials and implants for orbital floor repair. Acta Biomaterialia 7: 3248-3266.

Barradas AMC, Yuan H, van Blitterswijk CA, Habibovic P (2011) Osteoinductive biomaterials: current knowledge of properties, experimental models and biological mechanisms. Eur Cell Mater 21: 407-429.

Bat E, Plantinga JA, Harmsen MC, van Luyn MJA, Feijen J, Grijpma DW (2010) In vivo behavior of trimethylene carbonate and epsilon-caprolactone-based (co)polymer networks: Degradation and tissue response. J Biomed Mater Res A 95A: 940-949.

Benahmed M, Bouler JM, Heymann D, Gan O, Daculsi G (1996) Biodegradation of synthetic biphasic calcium phosphate by human monocytes in vitro: A morphological study. Biomaterials 17: 2173-2178.

Bergsma JE, Rozema FR, Bos RRM, DeBruijn WC, Boering G (1994) Poly(1-Lactic)acid implants in repair of defects of the orbital floor - a 5-year animal study. In: Bergsma JE: Late Complications Using Poly(lactide) Osteosyntheses: In Vivo and In Vitro Tests (Doctoral Thesis) Groningen, pp 37-48.

Cutright DE, Hunsuck EE (1972) The repair of fractures of orbital floor using biodegradable polylactic acid. Oral Surg Oral Med Oral Pathol 33: 28-34.

Dorozhkin SV (2009) Calcium orthophosphate-based biocomposites and hybrid biomaterials. J Mater Sci 44: 2343-2387.

Dupraz A, Delecrin J, Moreau A, Pilet P, Passuti N (1998) Long-term bone response to particulate injectable ceramic. J Biomed Mater Res 42: 368-375.

Dupraz A, Nguyen TP, Richard M, Daculsi G, Passuti $N$ (1999) Influence of a cellulosic ether carrier on the structure of biphasic calcium phosphate ceramic particles in an injectable composite material. Biomaterials 20: 663673.
Ellis E, Messo E (2004) Use of nonresorbable alloplastic implants for internal orbital reconstruction. $\mathrm{J}$ Oral Maxillofac Surg 62: 873-881.

Enislidis G (2004) Treatment of orbital fractures: The case for treatment with resorbable materials. J Oral Maxillofac Surg 62: 869-872.

Eppley BL, Prevel CD (1997) Nonmetallic fixation in traumatic midfacial fractures. J Craniofac Surg 8: 103-109.

Fellah BH, Gauthier O, Weiss P, Chappard D, Layrolle P (2008) Osteogenicity of biphasic calcium phosphate ceramics and bone autograft in a goat model. Biomaterials 29: 1177-1188.

Fellah BH, Delorme B, Sohier J, Magne D, Hardouin P, Layrolle P (2010) Macrophage and osteoblast responses to biphasic calcium phosphate microparticles. J Biomed Mater Res A 93A: 1588-1595.

Gauthier O, Bouler JM, Weiss P, Bosco J, Aguado E, Daculsi G (1999) Short-term effects of mineral particle sizes on cellular degradation activity after implantation of injectable calcium phosphate biomaterials and the consequences for bone substitution. Bone 25: 71S-74S.

Geesink RGT, Hoefnagels NHM, Bulstra SK (1999) Osteogenic activity of OP-1 bone morphogenetic protein (BMP-7) in a human fibular defect. J Bone Joint Surg-Br 81B: $710-718$.

Giannoudis PV, Dinopoulos H, Tsiridis E (2005) Bone substitutes: an update. Injury 36 Suppl 3: S20-27.

Greish YE, Brown PW (2001) Chemically formed HApCa poly(vinyl phosphonate) composites. Biomaterials 22: 807-816.

Guan LM, Davies JE (2004) Preparation and characterization of a highly macroporous biodegradable composite tissue engineering scaffold. J Biomed Mater Res A 71A: 480-487.

Habibovic P, Yuan HP, van der Valk CM, Meijer G, van Blitterswijk CA, de Groot K (2005) 3D microenvironment as essential element for osteoinduction by biomaterials. Biomaterials 26: 3565-3575.

Habibovic P, Yuan HP, Van den Doel M, Sees TM, van Blitterswiik CA, De Groot K (2006) Relevance of osteoinductive biomaterials in critical-sized orthotopic defect. J Orthopaed Res 24: 867-876.

Habraken WJEM, Zhang Z, Wolke JGC, Grijpma DW, Mikos AG, Feijen J, Jansen JA (2008) Introduction of enzymatically degradable poly(trimethylene carbonate) microspheres into an injectable calcium phosphate cement. Biomaterials 29: 2464-2476.

Ignatius AA, Betz O, Augat P, Claes LE (2001) In vivo investigations on composites made of resorbable ceramics and poly(lactide) used as bone graft substitutes. J Biomed Mater Res 58: 701-709.

Jansen J, Koopmans SA, Los LI, van der Worp RJ, Podt JG, Hooymans JMM, Feijen J, Grijpma DW (2011) Intraocular degradation behavior of crosslinked and linear poly(trimethylene carbonate) and poly(D,L-lactic acid). Biomaterials 32: 4994-5002.

Jaquiery C, Aeppli C, Cornelius P, Palmowsky A, Kunz C, Hammer B (2007) Reconstruction of orbital wall defects: critical review of 72 patients. Int J Oral Maxillofac Surg 36: 193-199. 
Kikuchi M, Koyama Y, Takakuda K, Miyairi H, Shirahama N, Tanaka J (2002) In vitro change in mechanical-strength of beta-tricalcium phosphate/ copolymerized poly-L-lactide composites and their application for guided bone regeneration. J Biomed Mater Res 62: 265-272.

Klein CPAT, Sauren YMHF, Modderman WE, Vanderwaerden JPCM (1994) A new saw technique improves preparation of bone sections for light and electron-microscopy. J Appl Biomater 5: 369-373.

Kontio R, Lindqvist C (2009) Management of orbital fractures. Oral Maxillofac Surg Clin North Am 21: 209220.

Kontio R, Suuronen R, Konttinen YT, Hallikainen D, Lindqvist C, Kommonen B, Kellomaki M, Kylma T, Virtanen I, Laine P (2004) Orbital floor reconstruction with poly-L/D-lactide implants: clinical, radiological and immunohistochemical study in sheep. Int J Oral Maxillofac Surg 33: 361-368.

Le Nihouannen D, Daculsi G, Saffarzadeh A, Gauthier O, Delplace S, Pilet P, Layrolle P (2005) Ectopic bone formation by microporous calcium phosphate ceramic particles in sheep muscles. Bone 36: 1086-1093.

Levitt SR, Crayton PH, Monroe EA, Condrate RA (1969) Forming method for apatite prostheses. J Biomed Mater Res 3: 683-684.

Liao H, Walboomers XF, Habraken WJEM, Zhang Z, Li Y, Grijpma DW, Mikos AG, Wolke JGC, Jansen JA (2011) Injectable calcium phosphate cement with PLGA, gelatin and PTMC microspheres in a rabbit femoral defect. Acta Biomaterialia 7: 1752-1759.

Malard O, Bouler JM, Guicheux J, Heymann D, Pilet P, Coquard C, Daculsi G (1999) Influence of biphasic calcium phosphate granulometry on bone ingrowth, ceramic resorption, and inflammatory reactions: Preliminary in vitro and in vivo study. J Biomed Mater Res 46: 103-111.

Marusic A, Katavic V, Grcevic D, Lukic IK (1999) Genetic variability of new bone induction in mice. Bone 25: 25-32.

Mathur KK, Tatum SA, Kellman RM (2003) Carbonated apatite and hydroxyapatite in craniofacial reconstruction. Arch Facial Plast Surg 5: 379-383.

Monroe EA, Votava W, Bass DB, Mcmullen J (1971) New calcium phosphate ceramic material for bone and tooth implants. J Dent Res 50: 860-861.

Nam SB, Bae YC, Moon JS, Kang YS (2006) Analysis of the postoperative outcome in 405 cases of orbital fracture using 2 synthetic orbital implants. Ann Plast Surg 56: 263 267.

Pego AP, Grijpma DW, Feijen J (2003a) Enhanced mechanical properties of 1,3-trimethylene carbonate polymers and networks. Polymer 44: 6495-6504.

Pego AP, Van Luyn MJA, Brouwer LA, van Wachem PB, Poot AA, Grijpma DW, Feijen J (2003b) In vivo behavior of poly(1,3-trimethylene carbonate) and copolymers of 1,3-trimethylene carbonate with D,L-lactide or epsilon-caprolactone: Degradation and tissue response. J Biomed Mater Res A 67A: 1044-1054.

Ploder O, Klug C, Voracek M, Burggasser G, Czerny C (2002) Evaluation of computer-based area and volume measurement from coronal computed tomography scans in isolated blowout fractures of the orbital floor. J Oral Maxillofac Surg 60: 1267-1272.

Potter JK, Ellis E (2004) Biomaterials for reconstruction of the internal orbit. J Oral MaxillofacSurg 62: 1280-1297.

Prowse SJB, Hold PM, Gilmour RF, Pratap U, Mah E, Kimble FW (2010) Orbital floor reconstruction: A case for silicone. A 12 year experience. J Plast Reconstruct Aesthet Surg 63: 1105-1109.

Ratner BD, Hoffman AS, Schoen FJ, Lemons JE (eds) (2004) Biomaterials Science: an Introduction to Materials in Medicine, 2nd ed. Elsevier Academic Press, New York.

Ripamonti U (1996) Osteoinduction in porous hydroxyapatite implanted in heterotopic sites of different animal models. Biomaterials 17: 31-35.

Rozema FR, Bos RRM, Pennings AJ, Jansen HWB (1990) Poly(l-Lactide) implants in repair of defects of the orbital floor - an animal study. J Oral Maxillofac Surg 48: 1305-1309.

Sinikovic B, Kramer FJ, Swennen G, T Luebbers H, Dempf R (2007) Reconstruction of orbital wall defects with calcium phosphate cement: clinical and histological findings in a sheep model. Int J Oral Maxillofac Surg 36: 54-61.

Tanner KE, Downes RN, Bonfield W (1994) Clinicalapplications of hydroxyapatite reinforced materials. $\mathrm{Br}$ CeramTrans 93: 104-107.

Taylor MS, Daniels AU, Andriano KP, Heller J (1994) 6 Bioabsorbable polymers - in-vitro acute toxicity of accumulated degradation products. J Appl Biomater 5: 151-157.

Urist MR (1965) Bone - Formation by autoinduction. Science 150: 893-899.

Urist MR, Silverman BF, Buring K, Dubuc FL, Rosenberg JM (1967) The bone induction principle. Clin Orthop 53: 243-283.

Van Leeuwen AC, Ong SH, Vissink A, Grijpma DW, Bos RRM (2012a) Reconstruction of orbital wall defects: Recommendations based on a mathematical model. Exp Eye Res 97: 10-18.

Van Leeuwen AC, Bos RRM, Grijpma DW (2012b) Composite materials based on poly(trimethylene carbonate) and beta-tricalcium phosphate for orbital floor and wall reconstruction. J Biomed Mater Res B Appl Biomater 100: 1610-1620.

Wu LB, Ding JD (2004) In vitro degradation of three-dimensional porous poly(D,L-lactide-co-glycolide) scaffolds for tissue engineering. Biomaterials 25: 58215830 .

Yuan H, van Blitterswijk CA, de Groot K, de Bruijn JD (2006a) A comparison of bone formation in biphasic calcium phosphate (BCP) and hydroxyapatite (HA) implanted in muscle and bone of dogs at different time periods. J Biomed Mater Res A 78A: 139-147.

Yuan H, Van Blitterswijk CA, De Groot K, De Bruijn JD (2006b) Cross-species comparison of ectopic bone formation in biphasic calcium phosphate (BCP) and hydroxyapatite (HA) scaffolds. Tissue Eng 12: 1607-1615.

Yuan HP, Kurashina K, de Bruijn JD, Li YB, de Groot K, Zhang XD (1999) A preliminary study on osteoinduction of two kinds of calcium phosphate ceramics. Biomaterials 20: 1799-1806. 
Yuan HP, Fernandes H, Habibovic P, de Boer J, Barradas AMC, de Ruiter A, Walsh WR, van Blitterswijk CA, de Bruijn JD (2010) Osteoinductive ceramics as a synthetic alternative to autologous bone grafting. Proc Natl Acad Sci USA 107: 13614-13619.

Zhang Z, Kuijer R, Bulstra SK, Grijpma DW, Feijen $\mathrm{J}$ (2006) The in vivo and in vitro degradation behavior of poly(trimethylene carbonate). Biomaterials 27: 1741-1748.

\section{Discussion with Reviewers}

A. Bernstein: While the ectopic bone formation by the composites at 3 months certainly implies that they possess some degree of osteoinductivity, the reviewer is not convinced that the addition of polymeric phase does not negatively impact the osteoinductivity of the BCP. This is primarily due to the fact that the $\mathrm{BCP}$ particles consistently demonstrated ectopic osteoinduction, while the $\mathrm{BCP} /$ polymer composites demonstrated only sporadic ectopic bone formation (presumably in the same animals). While the $\mathrm{BCP} /$ polymer composites did show bone formation at intraorbital sites, this could be due to osteoconduction (as evidenced by apparent low bone formation in surfaces not in contact with host bone) along with osteoinduction. This is further evidenced by the fact that there is lower bone formation in the PDLLA group in which the PDLLA serves as an initial barrier between the embedded BCP particles and host bone.

Authors: In the ectopic implantations of BCP, relatively large amounts of the ceramic induce bone formation. When implanting the composite materials, it should be realised that (1) much smaller amounts of the ceramic BCP phase are present and (2) these particles will only be able to induce bone formation upon erosion of the polymeric phase. Furthermore, at 6 and 9 months after intramuscular implantation both the polymer and the PTMC/BCP composites had almost completely resorbed, while in the case of BCP implantations BCP particles were still present at these time points due to the much larger amount initially implanted (see Fig. 8). Although osteoconduction and osteoinduction can occur simultaneously during the repair of the orbital floor, it is interesting to see in Fig. $3 \mathrm{H}$ that new bone has formed after 9 months at the centre of the implant (i.e., not in close contact with the host bone). For these reasons, we do not reach the same conclusion as the reviewer. In our opinion, the degrading polymer phase does not negatively influence the osteoinductive performance of the BCP phase, although we have not performed the experiment in which equal amounts of $\mathrm{BCP}$ and $\mathrm{BCP}$ in a PTMC/BCP composite were implanted.

A. Bernstein: Can the authors comment on possible synergestic effects of polymer resorption products and dynamic dissolution-reprecipitation of the BCP particles? Could the degradation products from PTMC/PDLLA influence osteoinductive properties of the BCP particles?
Authors: While it is known that the most often used lactide and glycolide (co)polymers can produce significant amounts of acidic compounds during degradation in the body, and that calcium phosphate ceramics and more importantly bone dissolve in acidic environments, it can be expected that these polymers will not be the most suitable matrix materials. In contrast, PTMC polymers do not produce acidic degradation products and therefore are likely to maintain osteoinductive properties. Besides its surface eroding properties, which allow the exposure and liberation of the osteoinductive particles during the degradation process, this was one of the main reasons for using PTMC in the composites.

A. Bernstein: Do the authors have any suggestions by which the polymeric phase could be further tuned to enhance or accelerate the defect healing? This is particularly intriguing based on the authors' proposal to study such composites with other ceramics as well.

Authors: As described in our previous work, the degradation rate of the PTMC matrix can be tuned by: (1). varying the molecular weight of the starting polymer, (2) varying the degree of crosslinking by adjusting the gamma irradiation dosage or (3) by preparing copolymers with a lactone such as $\varepsilon$-caprolactone. An appropriate preparing of copolymers with a lactone such that the degradation rate of the polymer will allow for sufficient scar tissue formation, since this is the main short term goal in orbital floor reconstruction. In addition, it would be of great interest to prepare a composite with higher BCP contents that still possesses good mechanical and handling properties.

D. Bosshardt: What was the reason for using the sheep for the testing of both ectopic bone formation and orbital floor reconstruction (OFR)?

Authors: Sheep models have often been used to assess bone formation experimentally. With regard to the orbit, the orbital volume of the sheep is larger than that of the human. This implies that the weight of its contents (eyeball, fat and muscles) will also be higher, putting higher loads on the orbital floor implant. From a mechanical point of view we can expect that when an implant performs well in a sheep model, it will also do so in humans. Nevertheless, it will remain necessary to conduct human trials as well.

D. Bosshardt: Can one expect that when a material is osteoinductive in sheep, it is also osteoinductive in humans?

Authors: The exact mechanism of osteoinduction by biomaterials is still incompletely understood. Currently it is known that the osteoinductivity of biomaterials is species and animal dependent: in small animals like rodents, bone is rarely induced by synthetic biomaterials. By contrast, bone formation is much more frequently observed in larger (sheep, goat, dogs) and higher (i.e., non-human primates) animals (Ripamonti (1996) text reference; Barradas et al. (2011) text reference). 

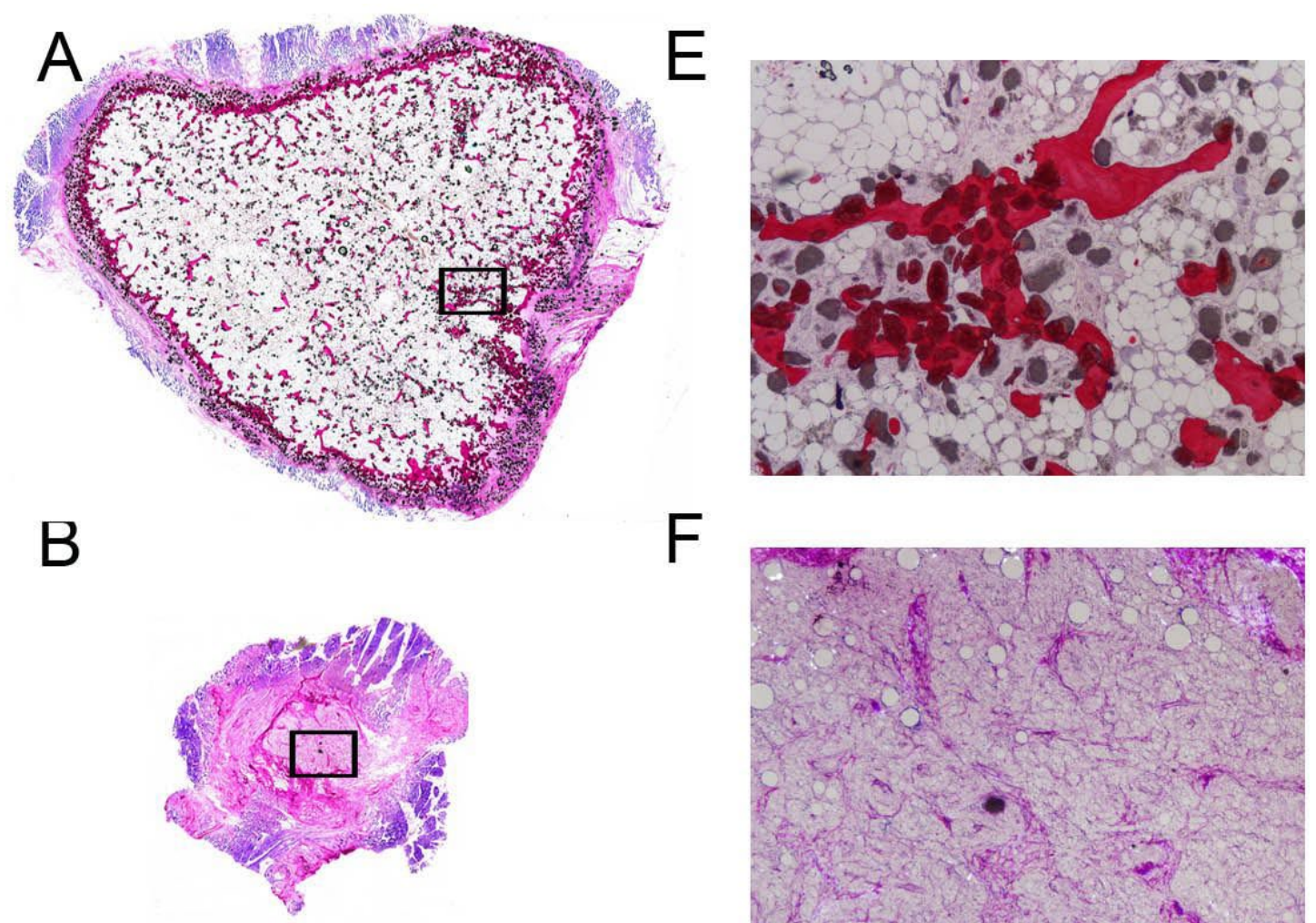

F

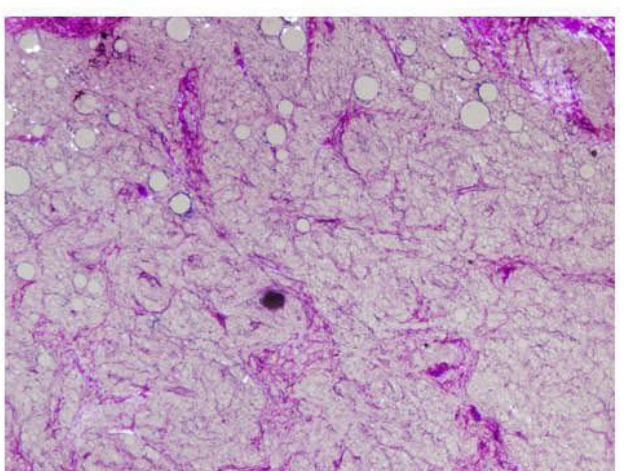

C

G
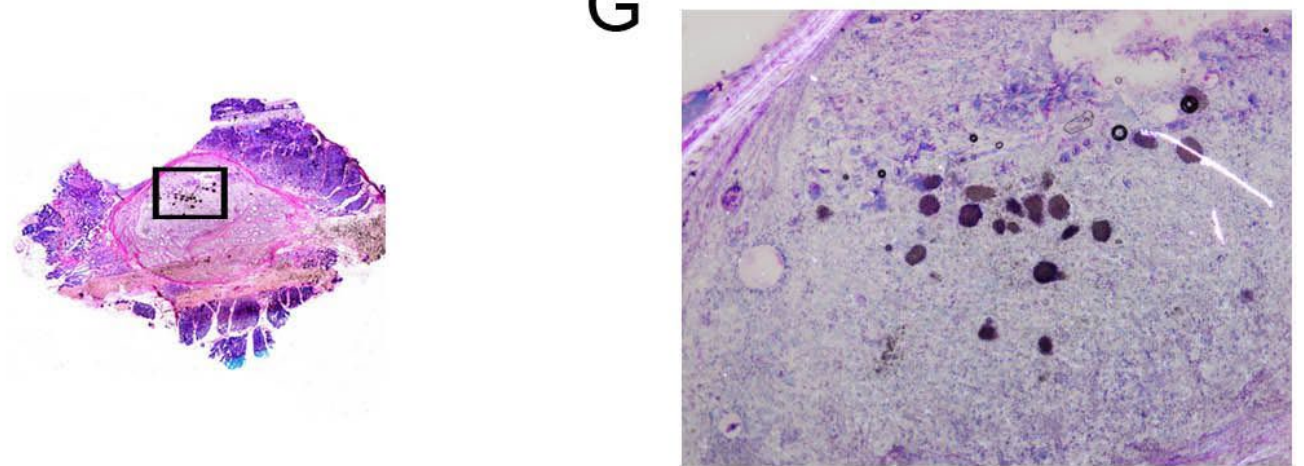

D
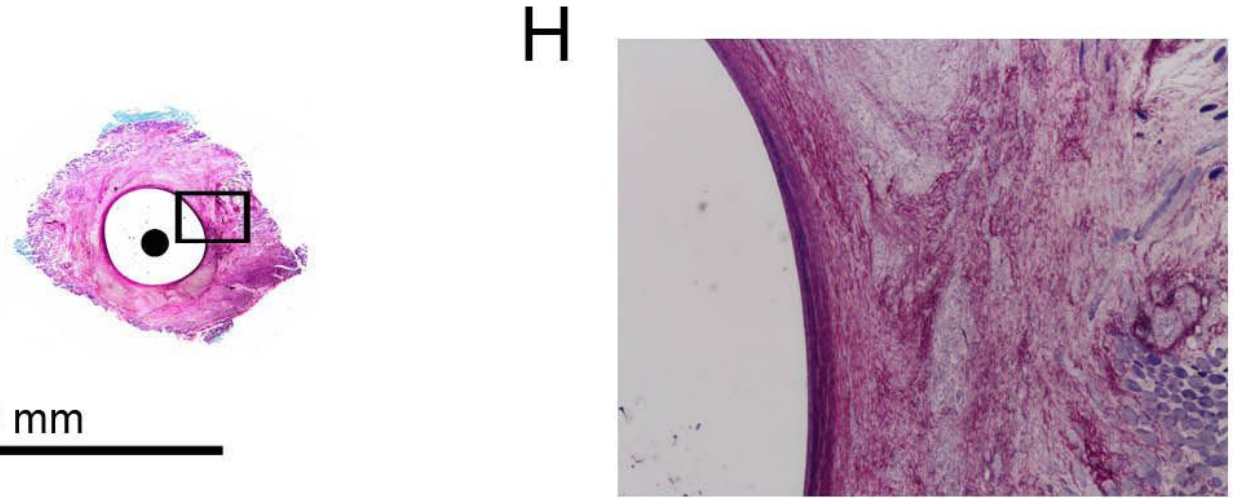

Fig. 8: Light micrographs of intramuscular implantation sites after 9 months. Images A-D represent details of intramuscular implantations of respectively BCP, PTMC/BCP composite, PTMC/BCP-PDLLA laminated composite and PTMC after 9 months. E-H represent overviews of the corresponding marked regions in image A-D. Bone formation upon implantation of the PTMC/BCP composites and the PTMC/BCP-PDLLA laminated composite could not be discerned at 9 months. $\mathbf{F}$ and $\mathbf{G}$ show that the polymeric components of the composites as well as the ceramic component had resorbed almost completely. The intramuscularly implanted PTMC sheets were still identifiable, although degradation had much progressed. The remaining material was surrounded by a fibrous capsule consisting of dense connective tissue. In accordance with Fig. 1, the black dots represent the BCP particles, also PDLLA polymer $(\boldsymbol{\bullet})$ and PTMC polymer $(\bullet)$ can be discerned. 